\title{
A importância da estratigrafia mecânica no desenvolvimento de falhas e juntas em contexto de bacias sedimentares: contribuição de modelos experimentais
}

\author{
The importance of mechanical stratigraphy in the development of faults and joints in \\ sedimentary basins: contribution from experimental models \\ Magda Estrela Oliveira ${ }^{1}$ e Fernando César Alves da Silva ${ }^{1,2}$ \\ 1 Universidade Federal do Rio Grande do Norte - UFRN, Programa de Pós-graduação em Geodinâmica e Geofísica, \\ Campus Universitário, Lagoa Nova, CP 1596, CEP 59078-970, Natal, RN, Brasil (magdaestrelaoliveira@gmail.com) \\ Universidade Federal do Rio Grande do Norte - UFRN, Departamento de Geologia, \\ Natal, RN, Brasil (fernando@geologia.ufrn.br)
}

Recebido em 8 de fevereiro de 2015; aceito em 4 de maio de 2016

\begin{abstract}
Resumo
A modelagem física analógica é atualmente uma ferramenta cada vez mais utilizada para melhorar o entendimento da formação e desenvolvimento das estruturas geológicas. O impulso dado na utilização dessa ferramenta deve-se, principalmente (mas não exclusivamente), à indústria do petróleo, onde a análise estrutural é importante para a definição da geometria das estruturas que possam constituir armadilhas para o hidrocarboneto. O presente trabalho analisa a nucleação de falhas e juntas, em função do contraste reológico de materiais analógicos, durante um evento distensional em bacias sedimentares. Influência de outros fatores, como espessura das camadas e seu posicionamento na estratigrafia, também foram analisados. Os materiais utilizados para simular uma estratigrafia mecânica foram pó de gesso (sulfato de cálcio semi-hidratado), microesferas de vidro e areia quartzosa. O monitoramento dos experimentos foi feito utilizando-se o PIV (Particle Image Velocimetry), instrumento que mostra a movimentação das partículas a cada instante deformacional. Como resultados, observaram-se diferenças na nucleação e desenvolvimento das falhas nas camadas de diferente comportamento reológico. As camadas de pó de gesso comportam-se de modo mais competente, permitindo a geração de um número maior de juntas, e as falhas apresentam mergulho mais elevado do que quando atravessam as camadas menos competentes de areia quartzosa. De forma geral, os experimentos podem ser interpretados como análogos da deformação frágil em rochas carbonáticas intercaladas em sequências siliciclásticas ou ricas em argilominerais, gerando armadilhas estruturais capazes de influenciar na migração e/ou armazenamento de fluidos, tais como hidrocarbonetos ou mesmo água subterrânea.
\end{abstract}

Palavras-chave: Modelagem física; Estratigrafia mecânica; Falhas normais.

\begin{abstract}
Analogue physical modeling is currently a tool increasingly used to improve the understanding of the formation and development of geological structures. The impulse given to the use of this tool comes mainly (but not exclusively) from the oil industry, where structural analysis is important in determining the geometry of structures that can constitute hydrocarbon traps. In this work, we analyzed the nucleation of faults and joints in a layered sequence composed of materials with different rheological behaviors during an extensional deformation event. Factors like layer width and stratigraphic position were also examined. To simulate a mechanical stratigraphy we used gypsum powder, glass beads and quartz sand. The experiments were monitored by using a PIV (Particle Image Velocimetry) apparatus, which shows the movement of the particles to each deformation moment. Thus, we observed differences in the nucleation and growth of faults in layers with different rheological behavior. The gypsum powder layers behave in a more competent mode, which allows the generation of a greater number of faults with higher dip angles, when compared to the less competent layers of quartz sand. These experiments could represent an analogue of brittle deformation in carbonate sequences intercalated with clay-rich or siliciclastic strata, where structural traps could play a main role in the migration and/or storage of fluids such as hydrocarbons or even groundwater.
\end{abstract}

Keywords: Physical modeling; Mechanical stratigraphy; Normal faults. 


\section{INTRODUÇÃO}

O desenvolvimento de estruturas frágeis em ambientes distensionais, principalmente em bacias sedimentares, tem sido objeto de estudo tanto em pesquisas acadêmicas como aplicadas e desenvolvidas pela indústria do petróleo. A modelagem física analógica, devido à sua capacidade bastante didática de simulação de estruturas geológicas, tem sido uma ferramenta importante para a indústria do petróleo, onde esta técnica é empregada tanto para identificar e compreender a geração de "trapas estruturais", responsáveis pelo acúmulo de hidrocarbonetos, como para o entendimento de processos sedimentares associados.

Na deformação de sequências estratificadas, a influência da estratificação mecânica e da espessura das unidades que as constituem são fatores importantes na definição do estilo estrutural de determinada área, conforme tem sido registrado em muitos trabalhos na literatura (Currie et al., 1962; McQuillan, 1973; Ladeira e Price, 1981; Bai e Pollard, 2000; Lorenz et al., 2002; Schöpfer et al., 2006; Ferrill e Morris, 2008; Zahm e Hennings, 2009). Zonas de falhas em sequências carbonáticas, por exemplo, são controladas pelo acamamento mecânico, onde falhas planares, de alto ângulo de mergulho, se desenvolvem em carbonatos maciços, enquanto nas camadas menos competentes, ricas em argila, se formam falhas com ângulo de mergulho mais baixo (Ferrill e Morris, 2008). Portanto, camadas com alto ângulo de fricção favorecem o desenvolvimento de falhas de mergulho elevado, enquanto o inverso ocorre em camadas de baixo ângulo de fricção (Peacock e Sanderson, 1992). Um fator também importante no desenvolvimento de estruturas em sequências rochosas é o contraste de viscosidade entre os materiais sob deformação (Ramsay e Huber, 1987). Os experimentos do tipo sandbox, diferentemente das simulações numéricas, não permitem considerar a dependência da viscosidade com a temperatura (Le Pourhiet et al., 2006). Os trabalhos realizados com materiais como silicone, mel, etc. discutem a influência da viscosidade em seus experimentos, mas consideram a viscosidade constante.

No presente trabalho analisou-se em vários experimentos de modelagem física a influência da estratigrafia mecânica e da espessura das camadas na nucleação e desenvolvimento de falhas normais e sistemas de juntas, durante uma distensão ortogonal. Analisou-se, também, o comportamento do rejeito de segmentos de falhas, quando essas atravessam materiais de comportamento mecânico distinto. A arquitetura final da deformação revelou-se dependente da reologia do material e, em menor grau, da espessura das camadas. Embora reconheçamos sua importância, mas a exemplo de outros trabalhos desenvolvidos com material granular (i.e. Panien et al., 2005), o fator viscosidade não foi abordado neste trabalho.

\section{MÉTODOS EXPERIMENTAIS}

\section{Modelagem física na geologia}

A modelagem física analógica tem como objetivo simular processos tectônicos e/ou sedimentares em escala de laboratório, para um melhor entendimento da geração e desenvolvimento de seus produtos. Com a evolução das técnicas de modelagem física analógica é possível atualmente aplicar essa ferramenta aos mais diversos temas geológicos, tais como a colocação de granitos (Berdiel et al., 1997; Berdiel, 1999), falhas normais em rochas carbonáticas (Fossen e Gabrielsen, 1996; Van Gent et al., 2010), dobras relacionadas a falhas (Withjack e Schlische, 2006), flanking structures (Exner et al., 2006), formação de bacias tipo rifte (Corti, 2012; Wu et al., 2013), subducção (Shemenda, 2012), colisão continental (Boutelier e Chemenda, 2011; Srivastava e Cobbold, 2014), deslizamentos de encostas (Ventisette et al., 2015), etc. Assim, a modelagem física (muitas vezes associada à modelagem numérica) é aplicada na simulação de processos atuantes, tanto em regime distensional quanto contracional (Keep e McClay, 1997; McClay et al., 2002; Vendeville et al., 2002; Liesa et al., 2006; Portugal e Alves da Silva, 2006; Alves da Silva e Oliveira, 2009; Cappelletti et al., 2011; Henza et al., 2011; Hengmao, 2012; Blanco et al., 2014).

A dimensão reduzida das estruturas nos modelos, bem como do tempo de sua formação nas simulações em laboratório, em relação ao ambiente geológico real, além de possibilitar a análise dos vários estágios de seu desenvolvimento, são as principais vantagens da aplicação desta ferramenta na resolução de um determinado processo geológico. Na modelagem física, um experimento é dito escalado quando há fatores de escala que descrevem a relação entre o modelo e o protótipo. Assim, tem-se o conceito de três similaridades importantes na modelagem: similaridade geométrica, quando as dimensões do modelo são $x$ vezes as dimensões equivalentes do protótipo; similaridade cinemática, quando o tempo necessário para o modelo mudar de forma, tamanho ou posição é $y$ vezes o tempo requerido para o protótipo sofrer mudanças similares; similaridade dinâmica, quando a razão entre todas as forças que atuam sobre o modelo e o protótipo são as mesmas (correlacionáveis por um fator de escala) em um sistema geométrica e cinematicamente similares.

Desde os primeiros experimentos realizados no século XIX por Sir James Hall (Koyi, 1997), a modelagem física analógica tem auxiliado para o melhor entendimento dos processos geológicos. A técnica permite analisar a evolução progressiva das estruturas e, assim, é utilizada não só em pesquisas puras como também nas aplicadas (Szatmari e Aires, 1987). Estas pesquisas possibilitaram a geração de novas ferramentas (imageamento da movimentação das partículas granulares, obtenção de dados "sísmicos" em aparato tipo caixa de areia, entre outros) que, associadas à caracterização de novos materiais (Rossi e Storti, 2003; Panien et al., 
2006; Gomes, 2013), são atualmente aplicadas/utilizadas na modelagem física. Os resultados obtidos com os modelos físicos podem ser usados em correlações com estruturas e com dados obtidos tanto em superfície como em subsuperfície (Naylor et al., 1994), dando maior robustez às interpretações geológicas.

Uma técnica, cuja aplicação na modelagem física analógica tem atraído crescente interesse, é a de Particle Image Velocimetry (PIV) (Adam et al., 2005), utilizada neste trabalho. Trata-se de um conjunto de câmeras fotográficas, controladas por softwares, que permite monitorar a movimentação das partículas nos experimentos analógicos a cada instante da deformação (Adam et al., 2005; Van Gent, 2005; Schmatz et al., 2010; Van Gent et al., 2010). A utilização de câmeras fotográficas de alta definição, que obtêm grande número de imagens em curto espaço de tempo, e o tratamento subsequente dessas imagens propiciam a elaboração de modelos 2D (como neste trabalho), 3D e 4D de experimentos analógicos (McClay et al., 2001, 2002).

\section{Materiais e equipamentos}

\section{Materiais}

Três tipos de materiais, com características distintas, foram utilizados: areia quartzosa, oriunda das dunas da cidade de Natal (RN), microesferas de vidro adquiridas da empresa Tecjato/Febratec e pó de gesso (Gesso São João Ind. Com. LTDA).

O pó de gesso (sulfato de cálcio semi-hidratado: $\mathrm{CaSO}_{4} \cdot 1 / 2 \mathrm{H}_{2} \mathrm{O}$ ) apresenta como características físicas cristais de formas irregulares com tamanhos da ordem de 10 a 400 $\mu \mathrm{m}$ e densidade de aproximadamente $730 \mathrm{~kg} / \mathrm{m}^{3}$. A areia quartzosa possuía granulometria fina entre 100 a $400 \mu \mathrm{m}$ com grãos subarredondados e subangulosos e densidade de $1350 \mathrm{~kg} / \mathrm{m}^{3}$, enquanto as microesferas de vidro apresentaram granulometria da ordem dos 70 a $100 \mu \mathrm{m}$ (esfericidade mínima de $80 \%$ ) e densidade estimada de $1480 \mathrm{~kg} / \mathrm{m}^{3}$, similar à utilizada por Panien et al. (2006).

\section{Equipamentos}

\section{Caixa de areia}

Nos experimentos foi utilizado um aparato do tipo "caixa de areia" com as dimensões de $50 \mathrm{~cm} \times 34 \mathrm{~cm} \times 24 \mathrm{~cm}$ (comprimento, largura e altura, respectivamente), constituída de três paredes fixas, de vidro transparente, e uma parede móvel (Figura 1). A parede móvel é conectada a um motor que a move a uma velocidade constante de $0,42 \mathrm{~mm} \cdot \mathrm{s}^{-1}$. $\mathrm{O}$ material utilizado foi peneirado na caixa, de uma altura aproximada de $20 \mathrm{~cm}$.

Para simular a formação de falhas em uma bacia tipo rifte com distensão ortogonal à direção de transporte tectônico, foi colocada uma folha de papel vegetal na base da caixa de experimentos. Esta folha, denominada descontinuador de velocidade $(\mathrm{Dv})$, é presa na parede móvel da caixa e induz a localização do rifte, durante a extensão (Figura 1).

\section{Particle Image Velocimetry (PIV)}

Segundo Adam et al. (2005) o PIV é um método óptico utilizado para o estudo de fluxo não linear e de visualização da deformação por técnicas de correlação de imagens ópticas. A precisão da medida de deslocamento feita com o PIV é de uma partícula de areia chegando a 0,1 pixel. O monitoramento do deslocamento de partículas granulares (no caso específico da modelagem geológica) é feito pela correlação óptica das imagens obtidas durante o processo de deformação. No processamento das imagens é possível realizar medições em alta resolução dos padrões da deformação incremental ao longo de um experimento em 2D ou 3D, tanto nas zonas deformadas como no material circundante. Assim o PIV, concebido inicialmente para o estudo de gases, é hoje uma

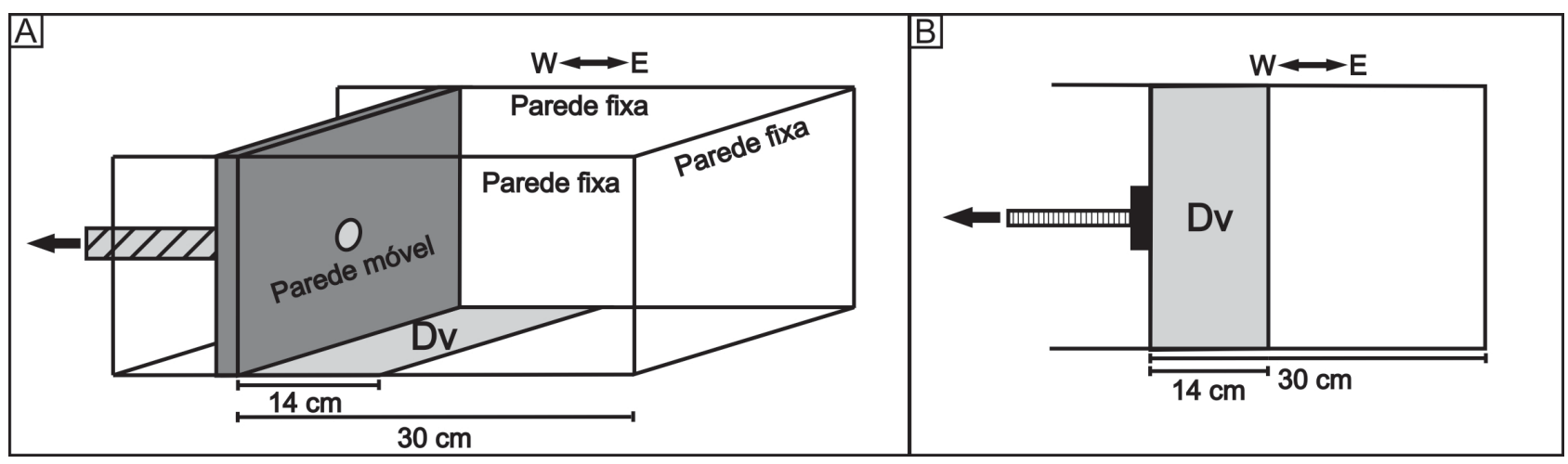

Figura 1. (A) Desenho esquemático da caixa de areia com o descontinuador de velocidade (Dv) usado nos experimentos; (B) Esquema da base da caixa de areia (vista em planta) com o Dv. A orientação EW foi feita de maneira arbitrária, com a finalidade de facilitar a descrição das falhas ao longo do texto. 
ferramenta importante na modelagem física analógica. A Figura 2 mostra esquematicamente a montagem do sistema PIV durante a realização dos experimentos discutidos neste trabalho. O processamento das imagens foi feito utilizando-se o software DaVis8 de LaVision.

\section{Configuração dos experimentos}

Para avaliar a importância do contraste reológico no desenvolvimento de falhas e juntas variaram-se, em quatro experimentos (MO-1, MO-1A, MO-2 e MO-3), além dos materiais analógicos (pó de gesso, areia quartzosa, tanto natural como tingida, e microesferas de vidro), a sequência estratigráfica e a espessura de camadas (Figura 3). Em um modelo (experimento MO-1A), também foi analisado o papel da sedimentação sintectônica. Todos os experimentos foram montados com espessura inicial de $6 \mathrm{~cm}$ (Figura 3) e foram submetidos a uma distensão total de $5,0 \mathrm{~cm}$. As demais características dos experimentos são sumarizadas na Tabela 1.

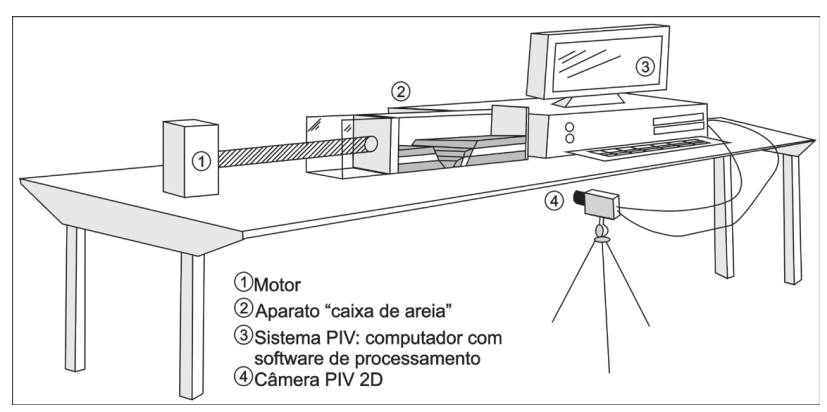

Figura 2. Esquema representativo da montagem do PIV utilizado neste trabalho.
Os quatro experimentos foram repetidos pelo menos três vezes, para confirmar a reprodutividade dos dados obtidos. O experimento MO-1 foi utilizado como experimento padrão para comparações, à medida que se mudavam as variáveis nos experimentos subsequentes: os materiais empregados $\mathrm{e}$ a espessura dos estratos, isto é, a sequência da estratigrafia mecânica. Todos os experimentos, à exceção do MO-1A, foram fotografados pelo sistema PIV, com a aquisição de 2 fotografias por segundo. No experimento MO-1A as fotografias foram obtidas a cada $0,5 \mathrm{~cm}$ de distensão.

\section{DESCRIÇÃO E INTERPRETAÇÃO DOS EXPERIMENTOS}

\section{Experimento MO-1}

O experimento MO- 1 mostrou que nos estágios iniciais, até aproximadamente $2,8 \%$ de distensão, a formação de estruturas foi relativamente reduzida em comparação com os estágios imediatamente subsequentes. Verificou-se que, enquanto as estruturas frágeis se desenvolviam na camada de pó de gesso, com $2,8 \%$ de distensão, a fina camada de areia dentro da camada superior de pó de gesso da porção oeste do modelo mostrava-se apenas arqueada, sem a presença de juntas ou falhas (Figura 4A e detalhe em B), enquanto que na porção leste, a falha de borda do graben já apresentava um desenvolvimento mais pronunciado, afetando todas as camadas (Figura 4A e detalhe em 4C). Com o aumento da deformação houve, então, o desenvolvimento de juntas de distensão abertas nas camadas de pó de gesso. Essas juntas evoluíram, em estágios mais avançados, para falhas normais de alto ângulo, controlando a formação do graben. Parte das juntas de alto ângulo, precursoras de falhas, pode ser

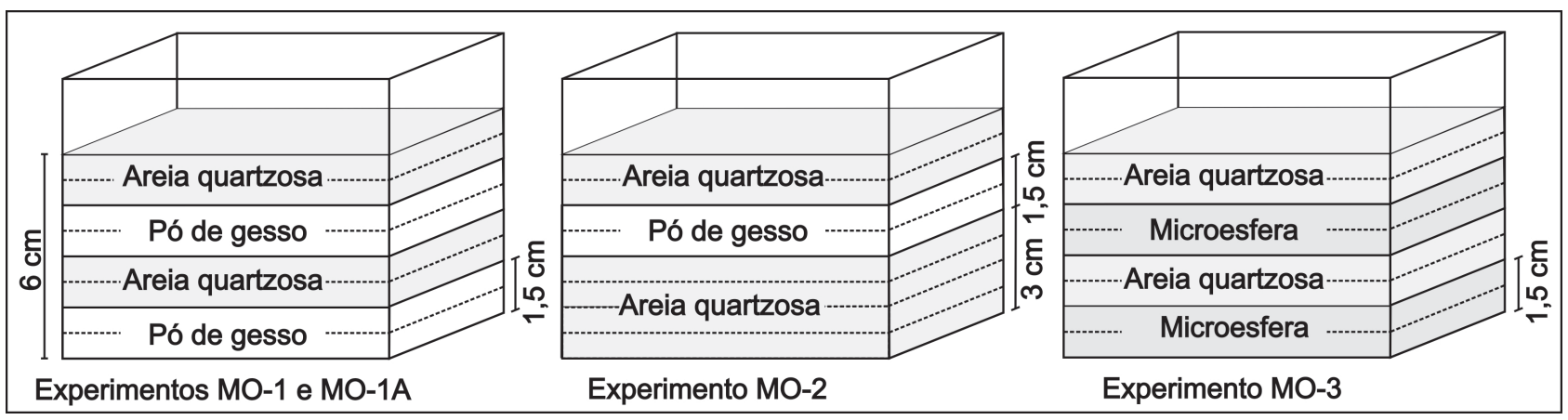

Figura 3. Esquema representativo da configuração estratigráfica dos experimentos. Os experimentos $\mathrm{MO}-1$ e $\mathrm{MO}-1 \mathrm{~A}$ têm a mesma configuração inicial, mas só em MO-1A houve sedimentação sintectônica. No experimento MO-2, a camada basal de areia tinha o dobro $(3 \mathrm{~cm})$ da espessura dos experimentos anteriores. O experimento MO-3 tem configuração similar à do experimento MO-1, porém substituiu-se o pó de gesso por microesferas de vidro. No meio de cada camada foi colocado um nível fino de areia tingida, para servir de marcador da deformação interna de cada camada (linha pontilhada, nesta figura). 
Tabela 1. Principais características dos quatro experimentos realizados.

\begin{tabular}{ccccc}
\hline Experimentos & Materiais usados & Espessura das camadas & $\begin{array}{c}\text { Sedimentação } \\
\text { sintectônica }\end{array}$ & Monitorado - PIV \\
\hline MO-1 & $\begin{array}{c}\text { Areia quartzosa, Pó de } \\
\text { gesso }\end{array}$ & $1,5 \mathrm{~cm}$ & Não & Sim \\
MO-1A & Areia quartzosa, Pó de & $1,5 \mathrm{~cm}$ & Não \\
gesso & Sim & Não & Não & Sim \\
MO-3 & Areia quartzosa, Pó de & $3,0 \mathrm{~cm}$ a camada basal e & 1,5 as demais \\
& Microesferas de vidro & $1,5 \mathrm{~cm}$ & & \\
\hline
\end{tabular}

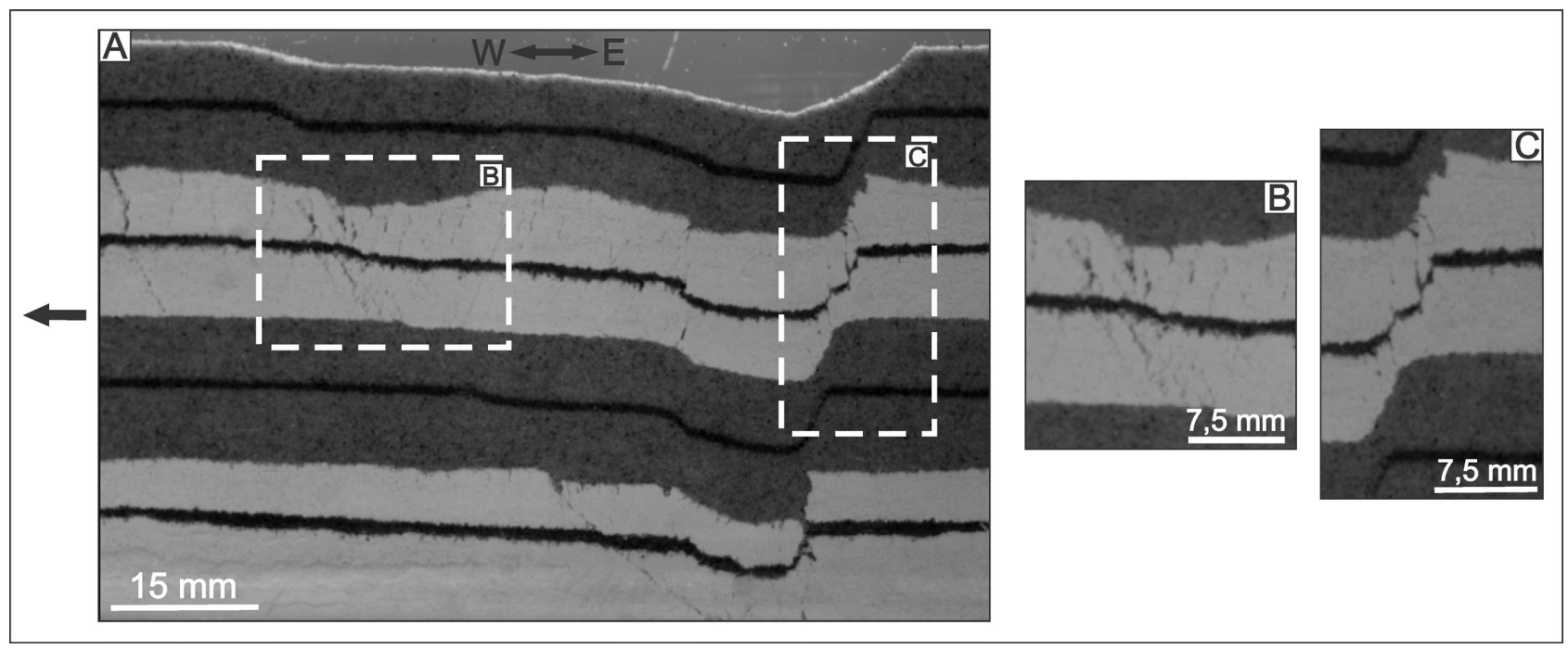

Figura 4. (A) Imagem de perfil do experimento MO-1, mostrando as estruturas formadas após 2,8\% de distensão; (B) Detalhe da porção W do modelo mostrando juntas abertas que, em estágio mais avançado da deformação, evoluíram para falhas de alto ângulo de mergulho, delineando a zona de borda W do graben; (C) Detalhe das falhas que, em conjunto, marcam a zona de borda E do graben. A seta indica o sentido da distensão. Nesta e demais fotografias apresentadas neste trabalho, as camadas de pó de gesso são representadas em tons de cinza claro e as camadas de areia em tons de cinza escuro e preto.

observada na extremidade oeste da camada superior de pó de gesso (Figura 4A e detalhe em 4B).

Mesmo com uma distensão relativamente pequena $(2,8 \%)$, já foi possível verificar a influência do contraste reológico na nucleação e desenvolvimento das estruturas frágeis. Com o aumento da distensão, o contraste da deformação nas camadas de diferentes materiais ficou ainda mais evidente. Enquanto que nas camadas de areia a deformação foi acomodada por um número pequeno de falhas, na camada superior de pó de gesso (entre as duas camadas de areia) o desenvolvimento de falhas foi mais expressivo. Estas falhas, na camada de pó de gesso, exibem alto ângulo de mergulho e são pouco espaçadas, gerando blocos de dimensões similares que rotacionaram, gerando um arranjo em dominó (Figura 5A).

$\mathrm{Na}$ camada basal de pó de gesso, dois subdomínios deformacionais puderam ser visualizados. No domínio leste, as falhas e juntas tendem a ser planares, fechadas, e a rotação dos blocos foi horária (Figura 5B). No domínio oeste, as juntas têm aspecto sigmoidal, são abertas e a rotação dos blocos foi anti-horária (Figura 5B). O espaço aberto pelas falhas e juntas é preenchido pela areia da camada sobreposta.

De forma geral, as falhas apresentaram-se constituídas de segmentos que mostraram comportamento distinto ao atravessarem diferentes camadas. Nas camadas de areia, o mergulho das falhas foi mais baixo e o deslocamento foi maior do que aquele nas camadas de pó de gesso (Figura 6A). Este comportamento é independente da espessura das camadas, uma vez que se repete nos estreitos níveis arenosos, que foram colocados dentro das camadas de pó de gesso como marcadores da deformação, conforme ilustrado na Figura $6 \mathrm{~B}$, que representa o estágio de $16,8 \%$ de distensão. Com a progressão da deformação, as falhas rotacionaram, diminuindo seu ângulo de mergulho. $\mathrm{O}$ arranjo estrutural final desse modelo foi caracterizado pela geometria em dominó 
dos blocos falhados da camada superior de pó de gesso. Nesta camada as falhas são planares e com espaçamento similar entre elas, resultando em blocos com dimensões similares (Figura 6A).

Ao contrário do que ocorre nas camadas de pó de gesso, as falhas nas camadas de areia não são desenvolvidas a partir de juntas distensionais. Este tipo de fratura não se desenvolve nas camadas de areia, devido ao fato da coesão da areia ser muito baixa (Faccenna et al., 1996; Schellart, 2000, entre outros). As falhas na camada de areia apresentam ângulos de mergulho em torno de $30^{\circ}$ e, ao longo do plano de falha, o estrato marcador é afinado, evidenciando a diminuição da

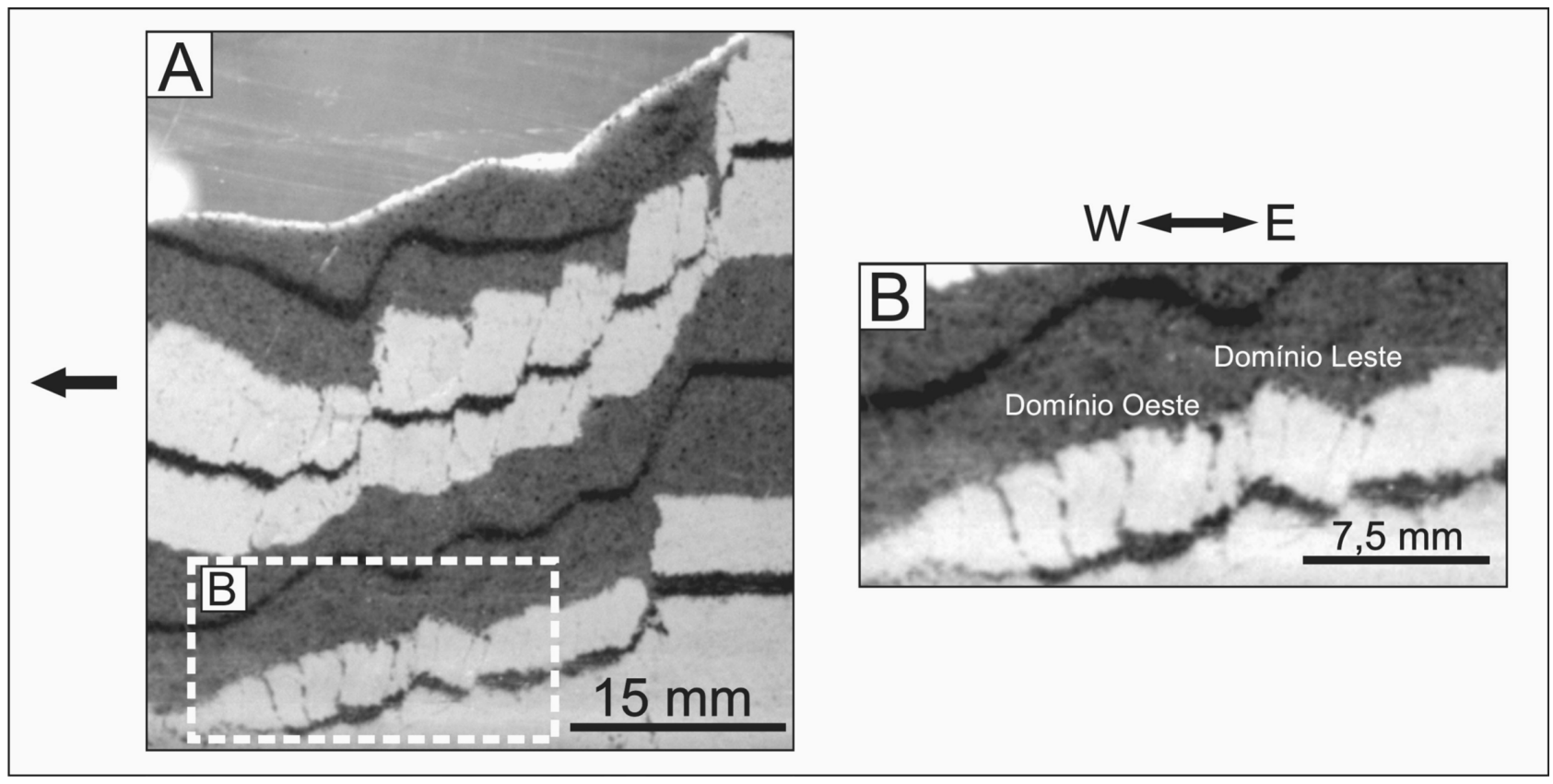

Figura 5. Imagens do experimento MO-1 após 14\% de deformação, mostrando a diferença das estruturas rúpteis nas diferentes camadas. (A) A camada superior de pó de gesso, entre as camadas de areia, mostra blocos limitados por falhas planares e com arranjo em dominó; (B) A camada basal de pó de gesso mostra rotação de blocos e falhas com planos sigmoidais.

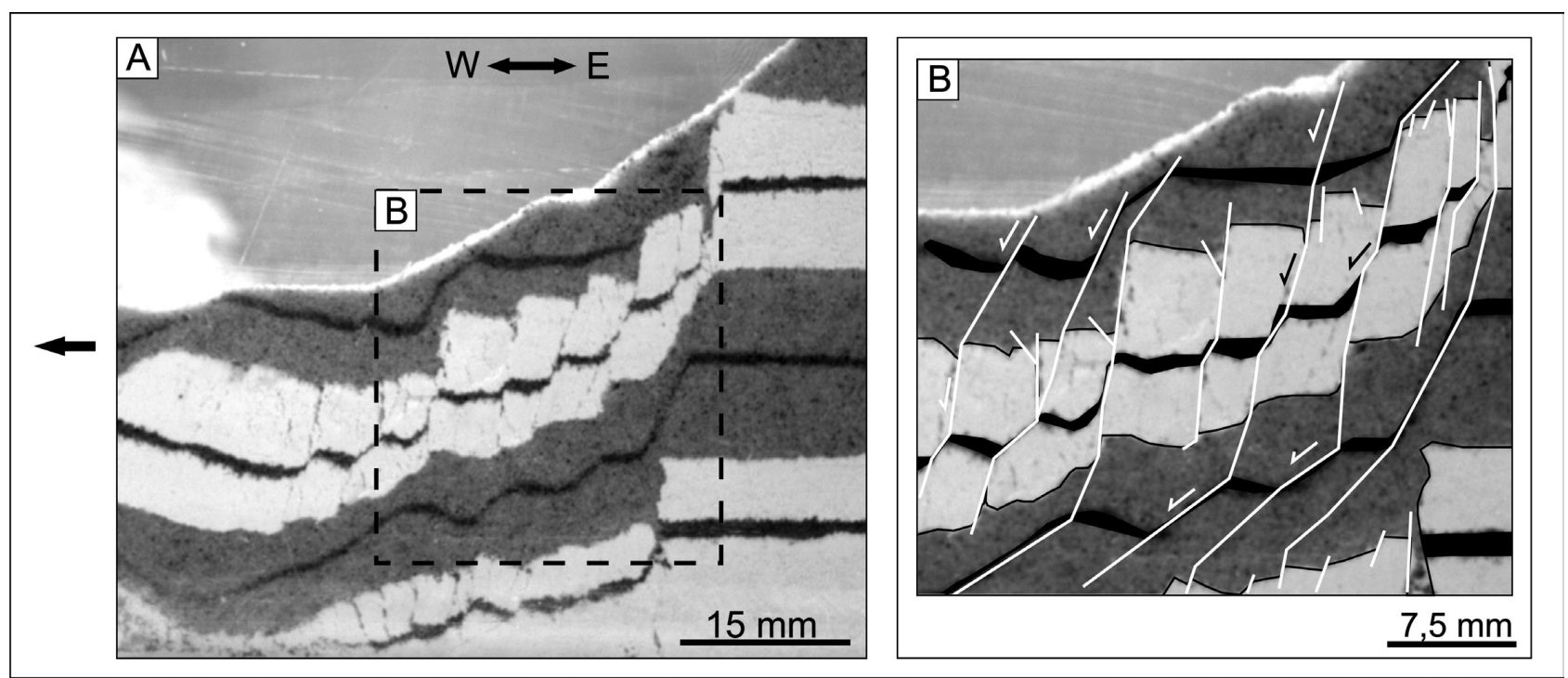

Figura 6. (A) Imagem do estágio final de deformação $(\varepsilon=16,8 \%)$, mostrando a rotação das falhas e a formação da geometria em dominó; (B) Detalhe da foto anterior mostrando que o contraste reológico influencia o comportamento da falha, mesmo nos níveis finos de areia tingida no interior da camada de gesso. 
espessura da camada, sugerindo um comportamento menos competente do que nos estratos de pó de gesso.

O monitoramento desse experimento com o PIV possibilitou avaliar, em detalhe, a evolução da deformação ao longo do tempo. O processamento das imagens obtidas durante os vários incrementos deformacionais mostrou os vetores de movimento das partículas granulares (Figuras 7A, 7B e 7C) e os locais onde a deformação se encontrava concentrada em um dado momento do experimento (Figuras 7D, 7E e 7F). Uma das vantagens da utilização do PIV é que ele permite marcar estes locais de concentração da deformação antes da visualização macroscópica.

Com a análise das imagens de incrementos deformacionais sucessivos foi possível observar a migração da deformação na bacia. Com $0,7 \%$ de distensão, a deformação apresentava-se concentrada na falha de borda leste. Nos incrementos

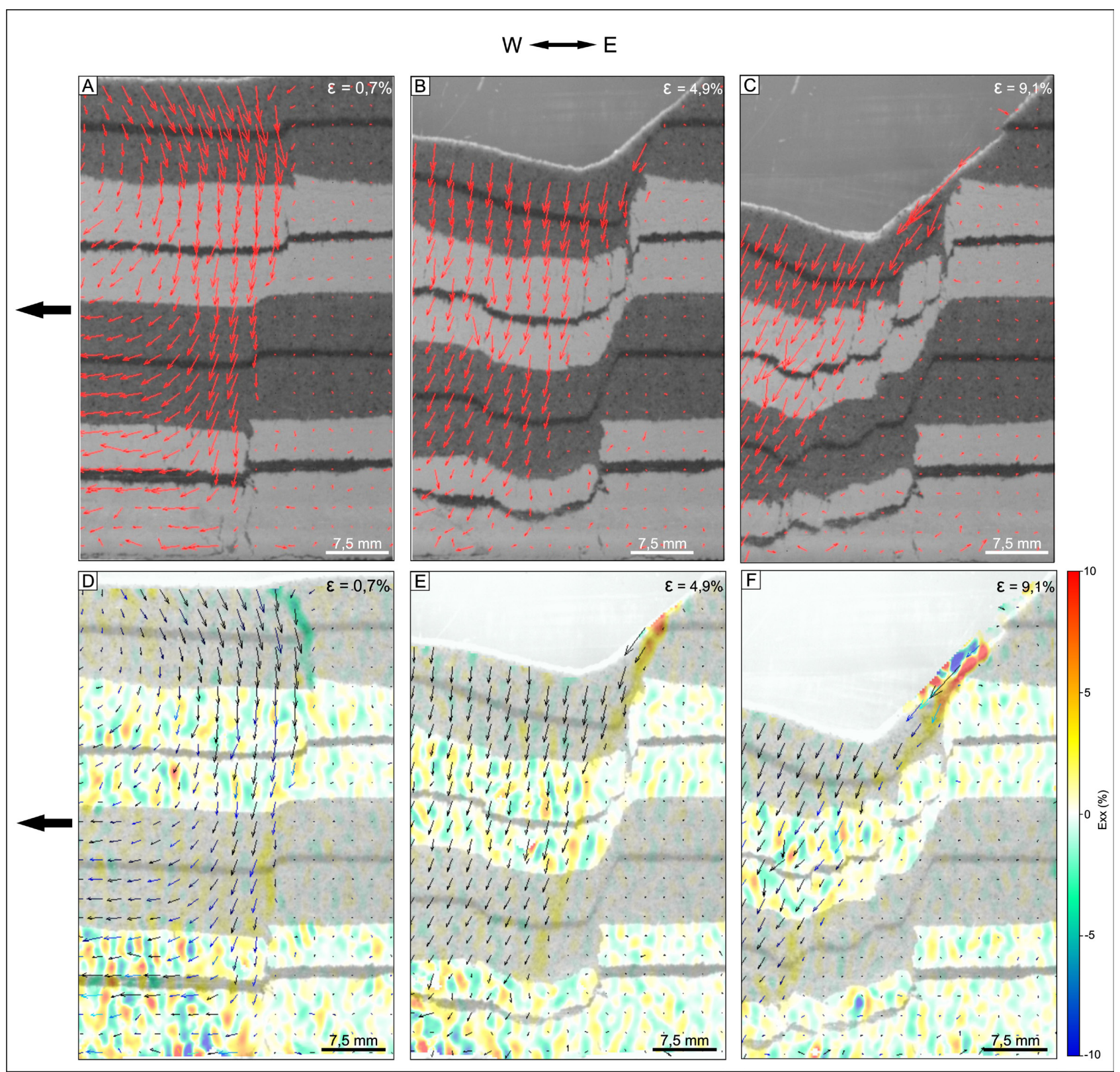

Figura 7. Exemplo de dados obtidos e processados pelo sistema PIV, relativo a três estágios deformacionais do experimento MO-1. Neste tipo de processamento, a movimentação das partículas granulares é mostrada pelas setas vermelhas cujo tamanho é proporcional à intensidade do seu movimento ( $A, B, C)$; As zonas de concentração de deformação, marcadas por faixas de cores diferentes (D, E, F), migraram de leste para oeste com o aumento da deformação (de 0,7\% a 9,1\%, nesta figura). 
distensionais subsequentes $(4,9 \%$ e $9,1 \%$, Figura 7$)$, a deformação migrou para o centro da bacia e, à medida que novas falhas eram geradas, algumas das falhas preexistentes se tornaram inativas (Figura 7). Esse processo resultou na migração para oeste do depocentro do graben.

\section{Análise do rejeito e da separação das falhas}

Verificou-se, em todos os experimentos, que os segmentos de falhas tinham comportamento distinto ao atravessarem camadas de materiais diferentes. Para analisar este comportamento, escolheu-se uma entre as diversas falhas geradas em cada um dos modelos (à exceção do MO-1A), e mediu-se o rejeito e a separação. A separação é entendida aqui como o deslocamento entre dois segmentos de uma camada específica, medido no sentido paralelo ao mergulho do plano de falha (como mostrado na Figura 8F). A separação é às vezes tratada na literatura como dip-separation.

No experimento MO-1, o rejeito da falha analisada na camada de pó de gesso é praticamente igual à separação, reflexo do ângulo de mergulho alto desta falha (Figura 8A). Quando a falha atravessa a camada de areia sotoposta à camada de pó de gesso, ela sofre rotação progressiva, diminuindo o seu ângulo de mergulho, de forma que a separação aumenta à medida que o rejeito da falha cresce (Figura $8 \mathrm{~B}$ ). Esta relação não se reproduz na camada menos competente, representada pelo fino estrato de areia interna à camada de pó de gesso. Neste estrato, a relação entre rejeito e a separação se mantém praticamente constante com a separação sendo sempre superior ao rejeito, devido à inclinação do plano de falha (Figura 8C). Quando comparados os segmentos de falhas nas três camadas analisadas (Figura 8F), nota-se que o fino estrato de areia interno à camada de pó de gesso exibe o maior rejeito e a maior separação, enquanto a camada de areia sotoposta mostra o menor rejeito e a camada de pó de gesso a menor separação (Figuras 8D e E).

\section{Experimento MO-1A}

Este experimento foi realizado com a adição de sedimentos sintectônicos representados por areia tingida, adicionada em intervalos de tempo regulares. As principais diferenças encontradas, em relação ao experimento sem sedimentação sintectônica, foram: o menor número de falhas geradas e, por esta razão, os blocos formados nas camadas mais competentes são mais largos e em menor número, e o basculamento (blocos e falhas), que também é menor (Figura 9). O ângulo de mergulho das falhas, quando estas atravessam as camadas de areia quartzosa, tanto pré como sintectônicas, é menor do que quando atravessam as camadas de pó de gesso, a exemplo do experimento anterior. A camada de pó de gesso basal apresenta falhas e juntas abertas, com preenchimento
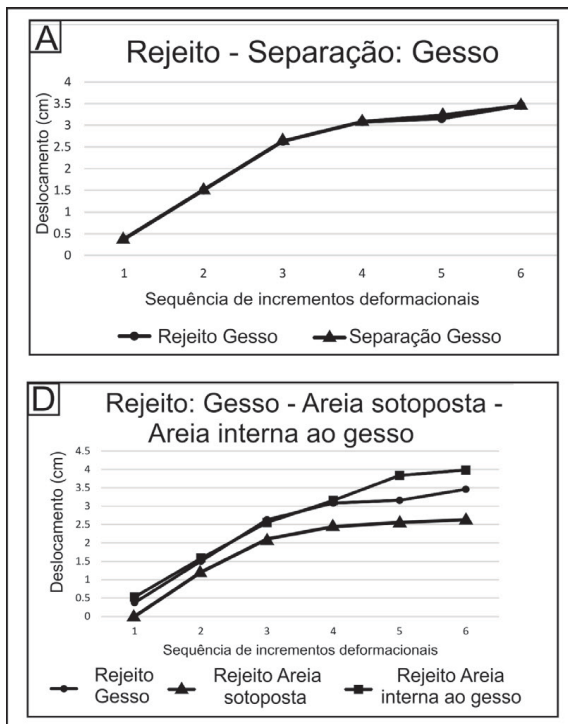
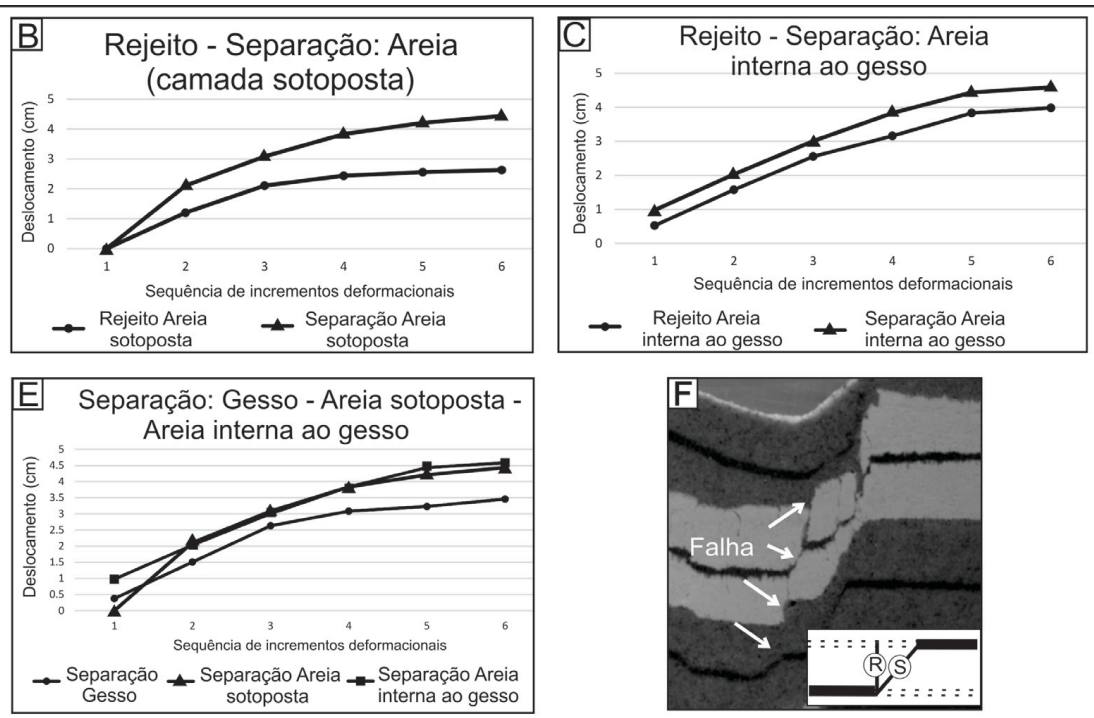

Figura 8. Relação entre Rejeito e Separação nas camadas mais e menos competentes do experimento MO-1. (A) Na camada mais competente (pó de gesso), o rejeito e a separação da falha são similares; (B) Na camada de areia (sotoposta à camada de pó de gesso), a separação é sempre maior que o rejeito; (C) No fino estrato de areia intercalada à camada de pó de gesso, o rejeito e a separação têm um comportamento relativamente constante, sugerindo que não houve rotação nesse segmento de falha; (D) e (E) mostram a relação entre rejeito e a separação nas três camadas analisadas. $O$ fino estrato de areia interno ao gesso possui o maior rejeito, enquanto a menor separação ocorreu na camada mais competente (pó de gesso); (F) Fotografia da falha analisada. No inset, as definições adotadas de rejeito e separação. 
do material sobrejacente (Figura 9). (Devido a limitações técnicas do sistema PIV, essa ferramenta não foi empregada neste experimento.)

\section{Experimento MO-2}

Neste experimento, o início do desenvolvimento de falhas foi mais tardio, se comparado com os experimentos anteriormente descritos (MO-1 e MO-1A). Novamente, as falhas (e juntas) apresentam-se mais verticalizadas no estrato de pó de gesso.
Um fato marcante foi o desenvolvimento de falhas "fora de sequência" na camada mais competente. Depois da nucleação da falha de borda (leste) do graben, falhas mais espaçadas desenvolveram-se no interior da bacia, delineando blocos mais largos (Figura 10A). Com o aumento da deformação, desenvolveram-se, progressivamente, novas falhas, agora no interior do bloco (limitado por falha "fora de sequência"), seccionando-o em fatias menores (Figuras 10B e 10C). Essas falhas tornaram-se inativas quando, com o aumento da deformação, uma nova falha (Fd na Figura 10D) foi

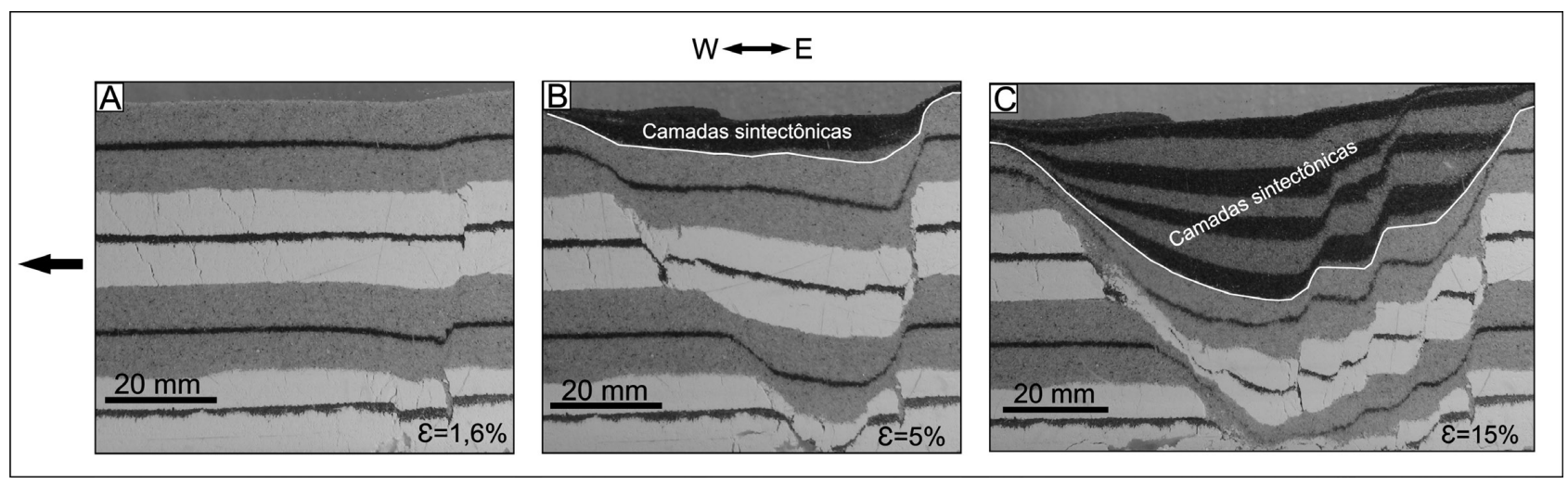

Figura 9. Fotografias de três estágios de deformação do experimento MO-1A. Nesse experimento, houve o desenvolvimento de blocos mais largos e um menor número de falhas que o experimento sem sedimentação sintectônica. (A) Deformação a $1,6 \%$ de distensão. Aparecimento de juntas e desenvolvimento da falha de borda na extremidade leste da figura. (B) Deformação a 5\% de distensão. Desenvolvimento do graben e preenchimento com as camadas sintectônicas. (C) Estágio final do experimento. Verifica-se um menor número de falhas formadas em relação ao experimento MO-1.

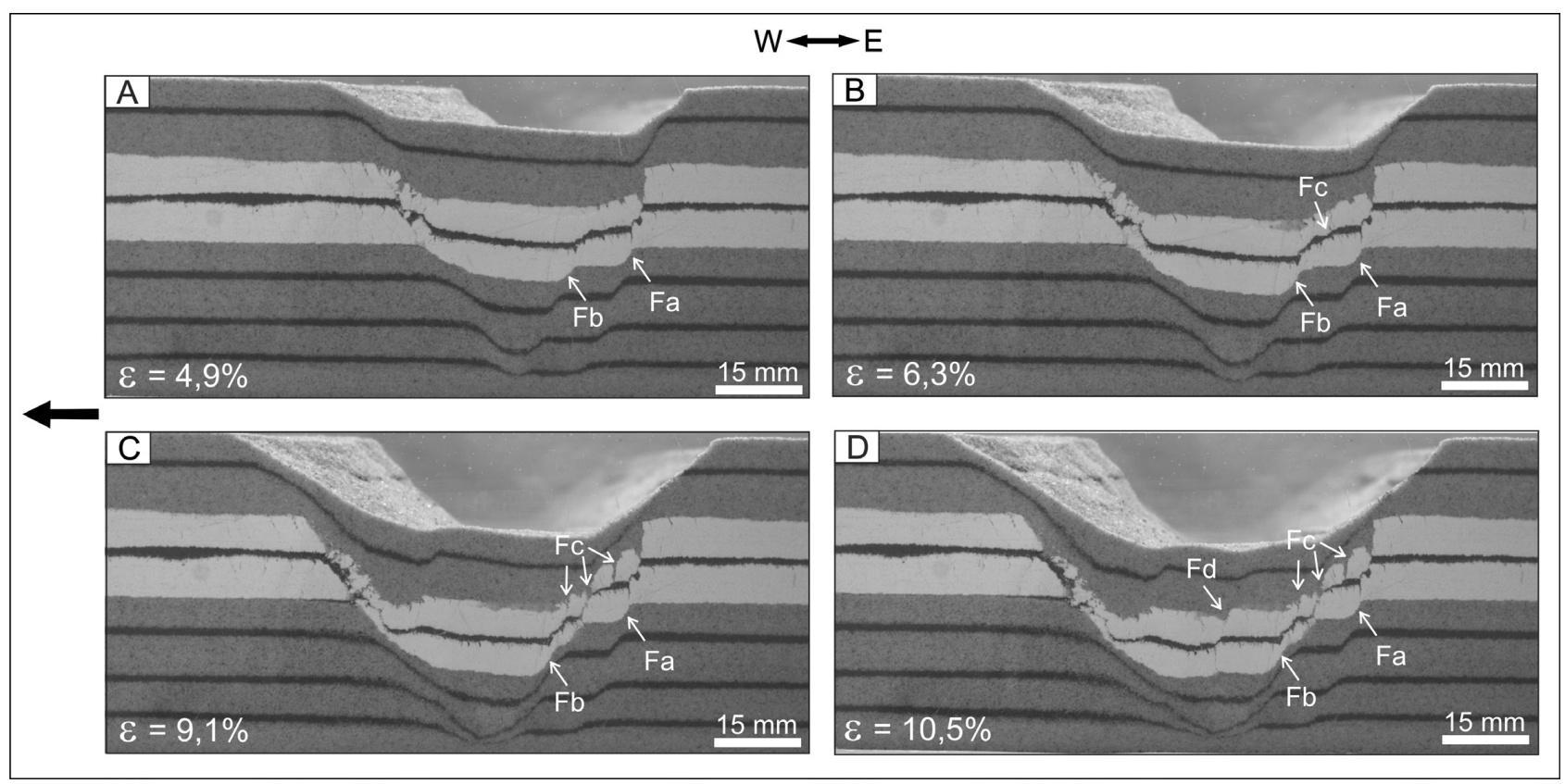

Figura 10. Fotografias de quatro estágios de deformação do experimento MO-2, mostrando o desenvolvimento progressivo de falhas. (A) Falhas Fa e Fb, nessa ordem, foram nucleadas, gerando um bloco largo nessa margem do graben; (B) e (C) Início e desenvolvimento de falhas "fora de sequência", dentro do bloco mostrado em (A); (D) Com a migração da deformação para o centro da bacia ocorreu a nucleação da falha Fd, gerando um novo bloco largo. 
desenvolvida, gerando um bloco mais espesso à frente do anterior, em direção ao centro do graben.

A cronologia de formação dessas falhas é bem marcada pelos dados do PIV, ilustrados na Figura 11. As zonas de falhas são delineadas por faixas de concentração de deformação, e a movimentação das partículas mostra que as falhas cresceram do topo para a base do experimento (o tamanho da seta é proporcional à intensidade da movimentação das partículas granulares na Figura 11). Com o aumento gradual da distensão $(2,8 \%, 4,2 \%, 7,7 \%$ e $10,5 \%)$, a deformação migrou para oeste, a partir da falha de borda (Fa na Figura 11), com a geração de novas falhas em direção ao centro da bacia. As falhas mais antigas situadas a leste da bacia tornaram-se inativas (Figura 11).

\section{Análise do rejeito e da separação das falhas}

Nesse experimento, o estrato mais competente ficou situado entre dois estratos menos competentes, sendo que o basal tinha duas vezes a espessura do superior (Figura 3). Assim, analisou-se o rejeito e a separação nessas três camadas. Não foi analisada a fina camada de areia interna à camada de gesso. A Figura 12A mostra que, no estrato mais competente, a intensidade da separação e o rejeito da falha são muito próximos, embora esse último seja sempre um pouco maior que o primeiro. O comportamento destes elementos da falha no estrato menos competente e mais espesso da base da sequência (areia inferior, Fai na Figura 12) é distinto daquele do estrato superior, menos espesso e menos competente (areia superior, Fas na Figura 12). Tanto o rejeito como a separação da falha na camada inferior são de menor amplitude, quando comparados àqueles da camada superior (Figura 12B). Até cerca de 12\% de distensão, o maior rejeito é registrado na camada mais competente, de pó de gesso. Para valores de distensão superiores a 12\%, o rejeito na camada de areia acima da camada de pó de gesso passa a ser maior, enquanto a inferior foi a que apresentou o menor rejeito durante todo o experimento (Figura 12C). Quanto à separação, a camada de gesso, mais competente, apresentou valores intermediários entre a camada de areia basal e de topo, essa última com valores mais elevados (Figura 12D). O conjunto desses dados é apresentado na Figura 12E, enquanto a Figura 12F mostra foto do modelo com discriminação dos segmentos da falha analisada.

\section{Experimento MO-3}

Nessa sequência de experimentos utilizaram-se camadas de microesferas de vidro, material de comportamento mais dúctil, em substituição ao pó de gesso. As demais configurações foram mantidas iguais àquelas do experimento MO-1 .

Embora tenham apresentado desenvolvimento distinto, as falhas de borda do graben apareceram bem evidenciadas com 2,8\% de distensão. A falha da borda leste (Fa na Figura 13A) afetou toda a coluna, sem diferenças significativas ao atravessar as diversas camadas, que continuaram sub-horizontalizadas (as camadas superiores mostram uma pequena inclinação em direção à falha). Na extremidade oeste do graben, a falha $\mathrm{Fb}$ (Figura 13A) desenvolveu-se a partir da base da sequência e, nesse estágio deformacional, não apresentou rejeito mensurável na camada superior, apesar dos dados fornecidos pelo PIV mostrarem a presença de concentração de deformação (Figura 13). A migração da deformação para a porção central da bacia ocorreu de forma relativamente rápida, com geração de uma nova falha (Fc, Figura 13B), que teve como consequência a inatividade da falha de borda $\mathrm{Fa}$ e o forte basculamento das camadas contra a nova falha (Figura 13B). Estas falhas (Fa e Fc) delimitam um bloco

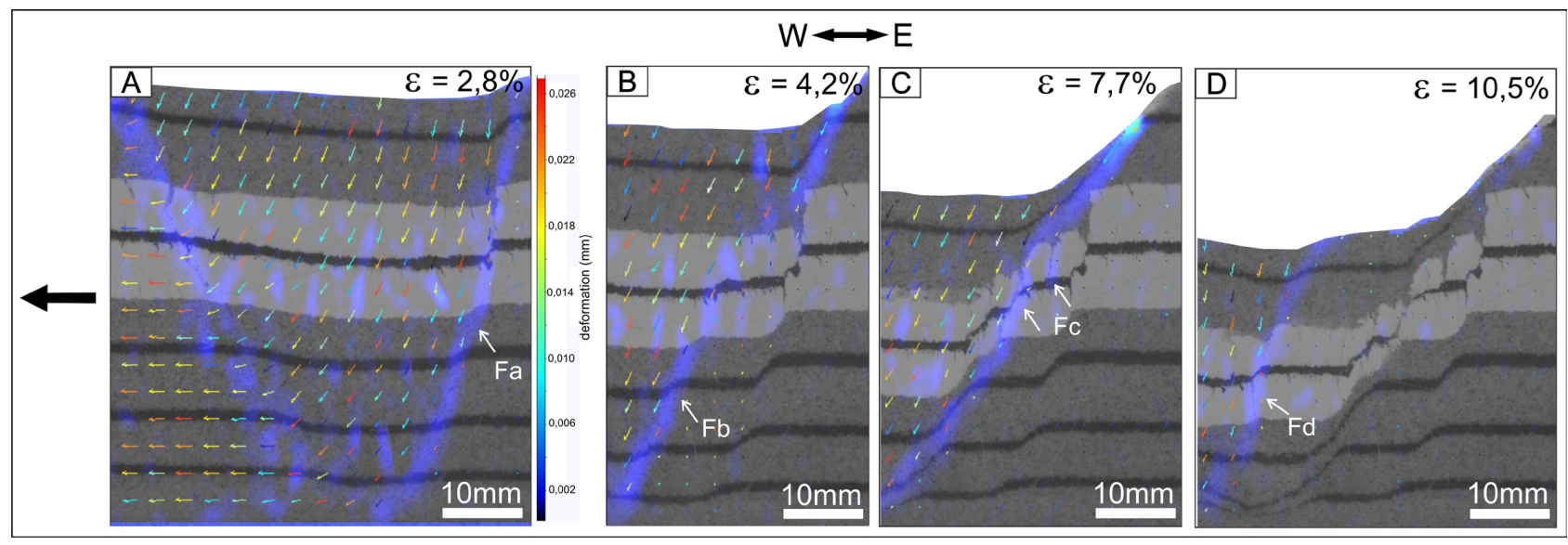

Figura 11. Quatro estágios deformacionais do experimento, mostrando a movimentação das partículas granulares (setas) e as zonas de concentração da deformação (faixas azuis). Dados obtidos com o PIV. (A) Formação das falhas de bordas (Fa); (B) Geração da falha Fb, que individualizou um largo bloco da camada de pó de gesso; (C) Desenvolvimento de falhas "fora de sequência" (Fc); (D) Com a geração da falha Fd, as falhas Fa, Fb e Fc tornaram-se inativas. 
relativamente largo e não basculado nessa porção do graben. $\mathrm{Na}$ camada de areia abaixo da camada de microesfera de vidro algumas falhas desenvolveram uma geometria bem curva, tendendo a lístrica, depois de cerca de $10 \%$ de distensão (Figura 13C). No geral, o experimento mostrou o desenvolvimento de blocos mais largos do que nos experimentos anteriores, limitados por falhas sem juntas distensionais ou brechas associadas (Figura 13C). Ao contrário, houve um estiramento das camadas ao longo da zona de deformação com consequente diminuição da espessura da camada de microesfera (Figura 13C).

\section{Análise do rejeito e da separação das falhas}

A análise dos parâmetros rejeito e separação foi feita em segmentos de uma das falhas que cortam as camadas de areia (superior e inferior) e a camada de microesfera de vidro superior. $\mathrm{Na}$ camada de microesfera de vidro, estes dois parâmetros foram de intensidade similar nos primeiros estágios da distensão. Entretanto, com a progressão da deformação, o crescimento da separação foi superior ao do rejeito (Figura 14A). Nos estratos de areia a separação foi sempre superior ao rejeito (Figuras 14B e 14C). No estrato
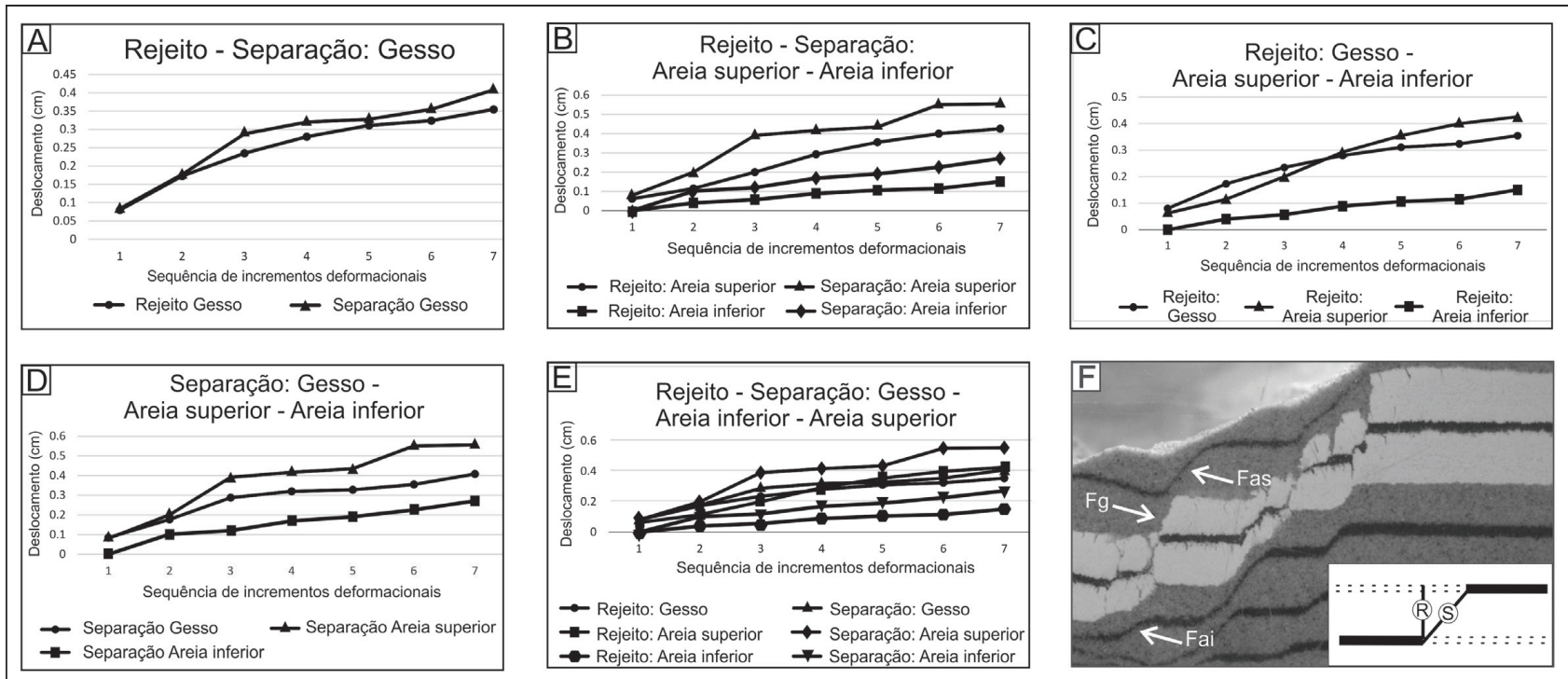

Figura 12. Dados de rejeito e separação de falha nos três estratos do experimento MO-2. (A) Na camada de pó de gesso a separação foi sempre um pouco maior que o rejeito; (B) Nas camadas de areia, o rejeito e a separação foram sempre maiores na camada superior (menos espessa); (C) Nos estágios iniciais, o maior rejeito ocorreu na camada de pó de gesso, mas foi suplantado por aquele da camada de areia superior (menos espessa); (D) As camadas de areia registram a maior e a menor separação, esta última na camada basal da sequência (mais espessa); (E) Rejeito e separação obtidos nas diversas camadas; (F) Fotografia do experimento com 14\% de distensão, ilustrando a localização dos segmentos de falhas analisadas. Fas = falha na camada de areia superior; Fai = falha na camada de areia inferior; Fg = falha na camada de pó de gesso. No inset, $R=$ rejeito e $S$ = separação.

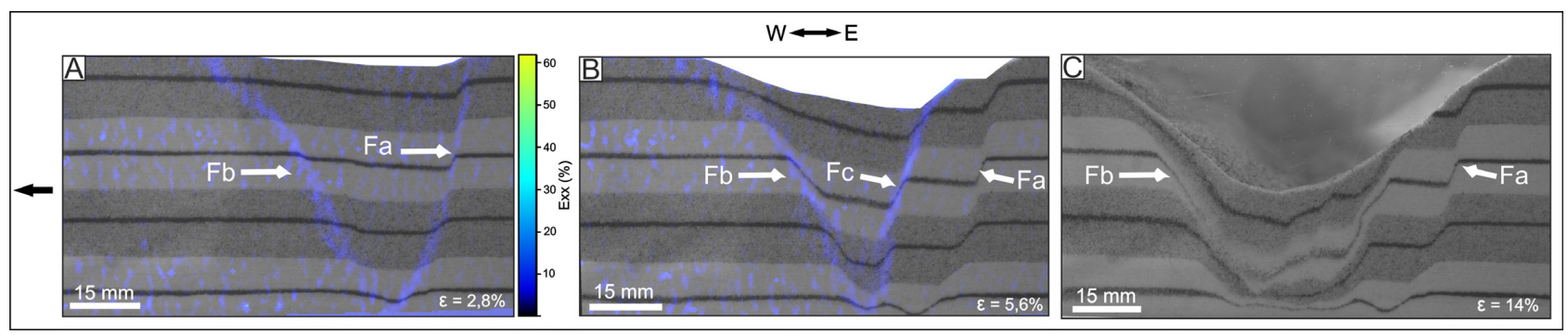

Figura 13. Fotografias de três estágios de deformação, mostrando o desenvolvimento das falhas no experimento MO-3. Em $\mathrm{A}$ e B, os dados do PIV marcam locais (faixas azuis) de concentração da deformação (zonas de falhas). (A) Geração de falhas de borda do graben (Fa, Fb). Notar a diminuição do rejeito de Fb em direção ao topo da sequência; (B) Desenvolvimento da falha Fc e desativação da falha Fa; (C) Desenvolvimento de novas falhas sintéticas a Fa. Não há geração de juntas abertas. 


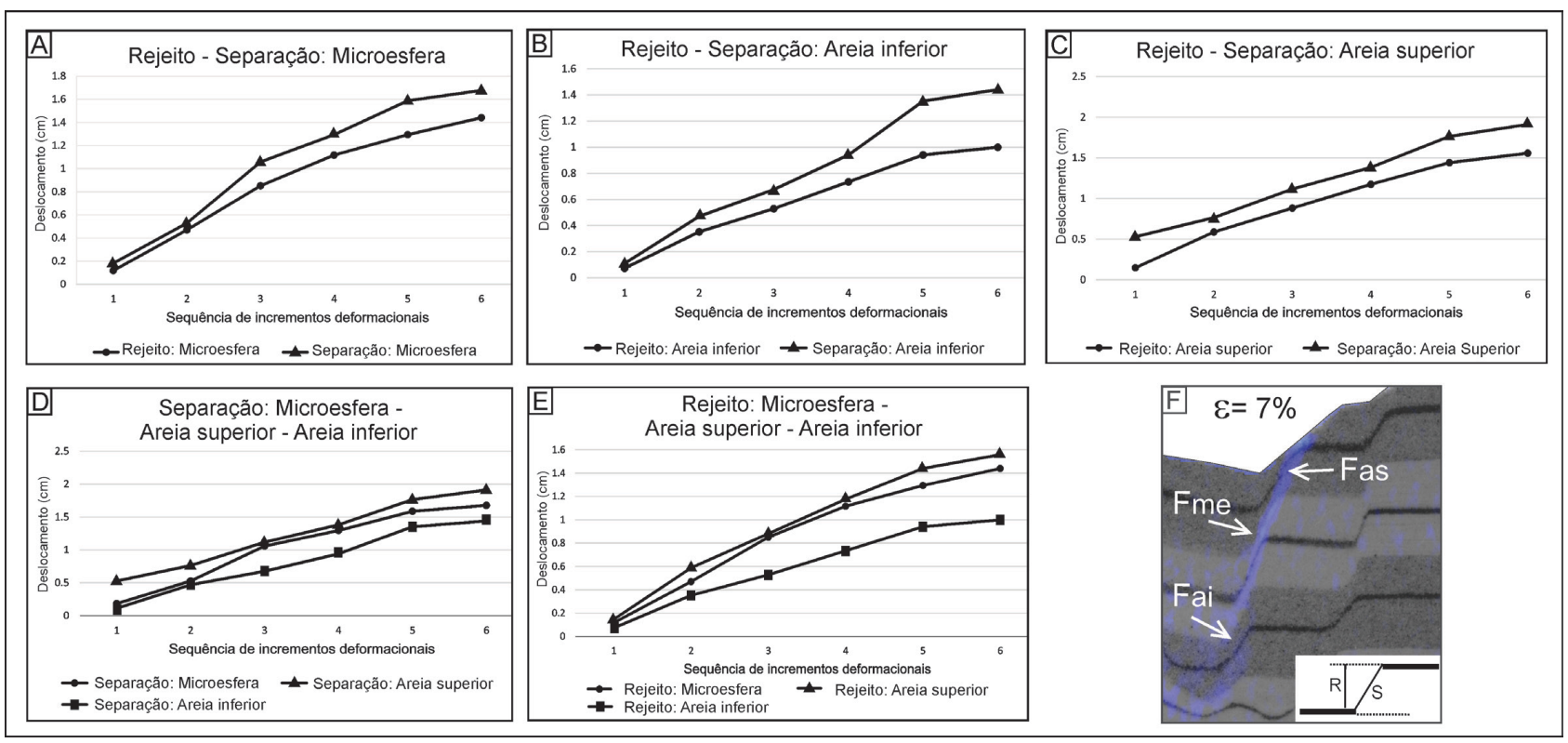

Figura 14. Comportamento do rejeito e da separação em falha do experimento MO-3. (A) Na camada de microesfera de vidro o rejeito foi sempre menor que a separação; (B) No estrato de areia inferior, o crescimento da separação foi sempre maior que o do rejeito; (C) No estrato de areia superior, rejeito e a separação tiveram comportamento semelhante. Em (D) e (E) a separação e o rejeito na camada de microesfera de vidro são menores do que aqueles da camada de areia sobreposta e maiores do que os da camada de areia sotoposta; (F) Fotografia da falha analisada: Fas = Segmento da falha na camada de areia superior, Fme= segmento da falha na camada de microesfera de vidro, Fai= segmento da falha na camada de areia inferior. No inset, $R=$ rejeito e $S=$ separação.

de areia superior, o crescimento destes dois parâmetros foi feito de forma mais homogênea, enquanto no estrato de areia inferior foi mais heterogêneo. Este fato foi atribuído à rotação da falha no estrato de areia superior, que apresenta mergulho mais baixo do que o segmento da falha desenvolvido no estrato de areia inferior (Figura 13B). Quando a falha secciona a camada de microesfera de vidro, a separação e o rejeito possuem valores intermediários entre aquele da areia superior (mais elevado) e o da areia inferior (mais baixo) (Figuras 14D e 14E).

\section{Formação de brecha cataclástica}

Durante os experimentos MO-1 e MO-2, observou-se a formação de brecha tectônica ao longo das falhas. A série de fotografias sequenciais, obtidas com o PIV (duas fotografias por segundo), possibilitou o monitoramento da formação incremental destas brechas. Dada a ocorrência comum desta feição em bacias sedimentares, comparou-se alguns estágios de sua formação nestes dois experimentos.

Durante o desenvolvimento da falha da borda oeste dos modelos MO-1 e MO-2, houve, no estrato de material competente (camada de pó de gesso), a formação de brechas tectônicas. Embora o resultado final possa apresentar semelhanças, os processos de nucleação e desenvolvimento das brechas nos dois modelos diferem entre si. No experimento MO-1, o processo ocorre no início da deformação $(\varepsilon=1,4 \%)$, com o aparecimento de fraturas de distensão e o arqueamento da camada de pó de gesso (Figura 15A). No estágio seguinte $(\varepsilon=5,6 \%$ ), a deformação é particionada em duas zonas denominadas zona de danos do hangingwall ( $\mathrm{Zdh}$ ) e zona de danos do footwall (Zdf) (Figura 15B). Neste estágio, o processo cataclástico é bem mais avançado junto a Zdf, desenvolvido paralelamente às juntas sintéticas que são destruídas para a criação das brechas. $\mathrm{Na} Z$ dh, ainda neste estágio deformacional, observou-se que muitas das juntas antitéticas ainda sobreviviam (Figura 15B). O processo cataclástico junto a $\mathrm{Zdh}$ ocorreu principalmente da base para o topo do estrato, diferentemente do que aconteceu na $\mathrm{Zdf}$ (Figura 15B). Durante a distensão, o material cominuído ora permaneceu in situ (brecha autóctone) ora migrou ao longo da falha (brecha alóctone) (Figura 15C). No experimento MO-2, o processo cataclástico iniciou mais tardiamente em relação ao MO-1 (comparar a Figura 15A com 15D e a Figura 15B com 15E). Em MO-2 houve também o desenvolvimento de pequenas falhas secundárias que, com o aumento da deformação, foram destruídas durante a cataclase, sendo o material incorporado à brecha em desenvolvimento (Figuras 15E e 15F). Não houve o desenvolvimento de falhas no footwall, como no experimento MO-1, e a brecha é essencialmente alóctone (Figura 15F). 


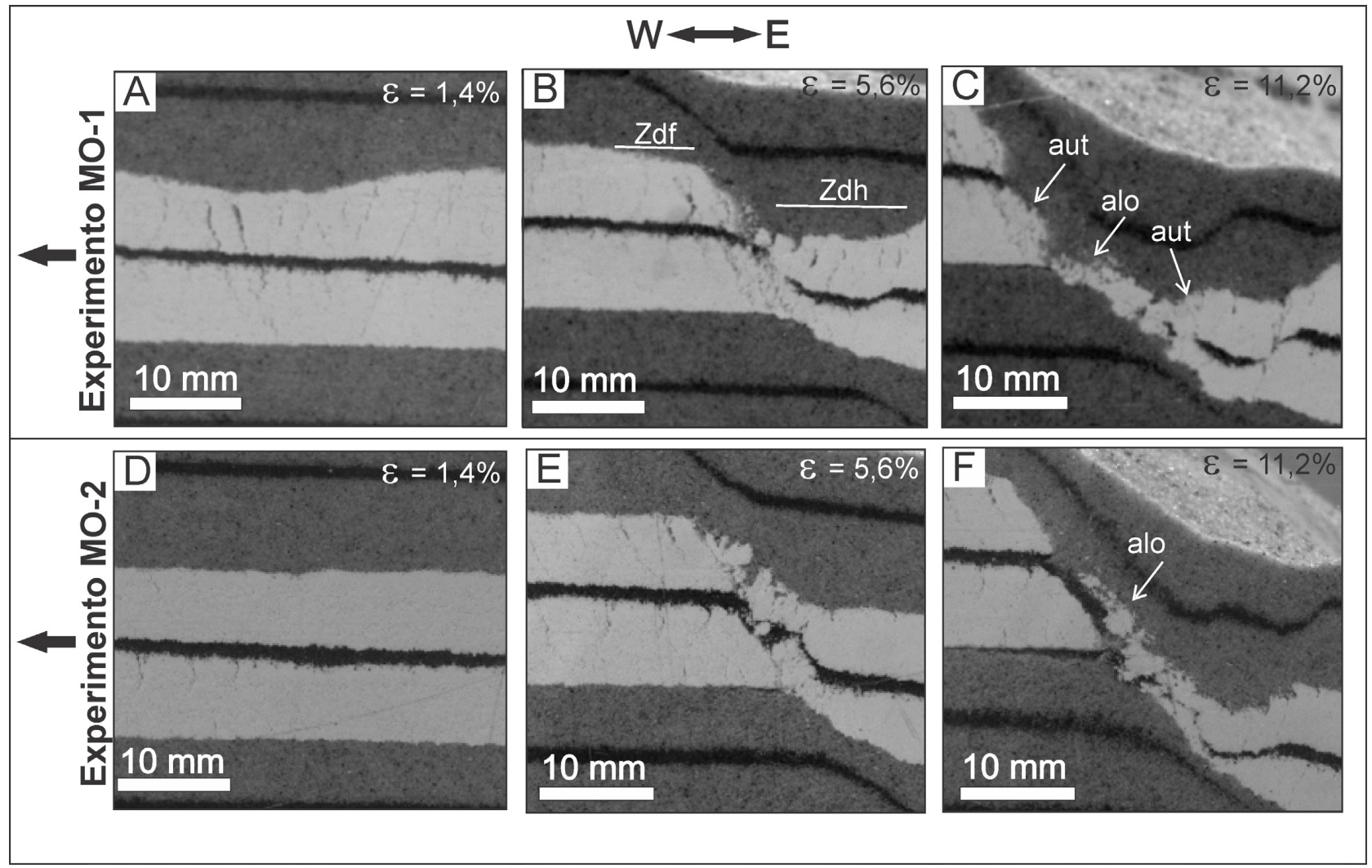

Figura 15. Formação de brechas cataclásticas nos experimentos MO-1 e MO-2. (A) e (D) mostram que o processo deformacional é mais precoce em MO-1; (B) e (E) ilustram o desenvolvimento da zona de falha, com formação de brecha cataclástica. Na Zdh de MO-1 ocorreu o desenvolvimento de pequenas falhas com planos curvos; $(C)$ e $(F)$ : com o aumento da deformação, o material cataclástico pôde deslocar-se, gerando porções alóctones (alo) nas zonas de falhas mais deformadas, ou permanecer relativamente autóctones (aut). Zdh = Zona de danos no hangingwall; Zdf = Zona de danos no footwall.

\section{DISCUSSÃO E CONCLUSÕES}

Os experimentos realizados mostram que a geometria de falhas normais e o arcabouço estrutural de uma bacia sedimentar sofre influência marcante do contraste reológico entre os estratos (competentes versus incompetentes). Este contraste pode estar relacionado a fatores primários, tais como a natureza reológica intrínseca das camadas, devido a sua composição original, ou é realçado por processos como diagênese, litificação, etc. Outros fatores que também têm influência nas características das falhas são as espessuras das camadas e a distribuição espacial destas na coluna estratigráfica.

\section{Comparação entre os diversos modelos}

\section{Geometria das falhas}

Os resultados obtidos neste trabalho revelaram que os segmentos de falhas sofrem refração ao passarem de um material menos competente para um mais competente.
Nos experimentos realizados, a camada de pó de gesso teve um comportamento reológico mais competente do que as camadas de areia situadas sub e sobrejacentemente (experimentos MO-1, MO-1A e MO-2). De uma maneira geral, as falhas desenvolvidas nos estratos mais competentes apresentaram-se planares e com mergulhos mais elevados do que aqueles nos estratos menos competentes. Este contraste angular dos planos de falhas pôde ser observado até nos finos níveis de areia colocados como marcadores da deformação dentro das camadas de pó de gesso.

A geometria das falhas, entretanto, depende não apenas das características físicas do material onde se propagam, mas também sofre influência da espessura do pacote sobreposto (carga litostática). Assim, o posicionamento da camada mais competente na coluna estratigráfica também contribuiu para a geometria das estruturas frágeis desenvolvidas. Este caso é exemplificado pelo experimento MO-1, onde as estruturas desenvolvidas nas camadas de pó de gesso basal e superior não são iguais. Enquanto falhas planares, formando arranjo em dominó, desenvolveram-se na camada superior, na camada basal houve o desenvolvimento de falhas 
e juntas com geometria sigmoidal e algumas delas foram rotacionadas. Esta diferença de configuração das estruturas é interpretada como devido à espessura da pilha de materiais acima da camada de gesso basal, que foi três vezes maior do que aquela acima da camada superior. Adicionalmente, o fato da camada inferior de pó de gesso não ter, na sua base, a camada de areia, uma vez que repousa diretamente sobre o Dv, pode ter contribuído, de forma secundária, para a diferença acima citada. A rotação anti-horária das juntas possivelmente ocorreu devido à inclinação da camada de pó de gesso em direção à falha de borda (W) do graben (Figuras 5C e 6A).

Falhas com geometria curva foram desenvolvidas na camada de areia quando essa estava entre duas camadas de comportamento reológico distinto do seu, sejam elas mais ou menos competentes. O primeiro caso ocorreu quando a espessura da pilha acima da camada de areia em questão aumentou devido à adição de material (areia tingida artificialmente) no topo do modelo (experimento MO-1A), simulando a sedimentação sintectônica (Figuras 9B e 9C). No segundo caso, as falhas curvas ocorreram na camada de areia entre as duas camadas de microesferas de vidro do experimento MO-3 (Figura 13C).

\section{Arquitetura estrutural dos modelos}

Nos três primeiros modelos, MO-1, MO-1A e MO-2, uma camada de pó de gesso, de mesma espessura, foi deformada entre duas camadas de areia quartzosa. Em todos estes experimentos, a camada de pó de gesso comportou-se de modo mais competente do que as camadas de areia. Quando submetida à deformação distensional, a camada mais competente formou blocos com arranjo em dominós (Figura 16). Esses blocos, entretanto, apresentaram uma configuração particular em cada experimento. Um maior número de falhas em MO-1 resultou na fomação de um número maior de blocos, que são menores do que nos demais modelos (Figura 16). As falhas mais espaçadas, gerando blocos mais largos na camada mais competente no experimento MO-1A, podem ser interpretadas como consequência da sedimentação sintectônica que produz uma maior compactação nas camadas pré-existentes, alterando assim o comportamento do pó de gesso. Em MO-2, onde a camada basal de material menos competente é duas vezes mais espessa do que nos demais modelos, a geometria dos blocos falhados sugere uma combinação entre os modelos MO-1 e MO-1A. Neste modelo houve o desenvolvimento de um conjunto de blocos menores, alternando-se com blocos mais largos (Figura 16). Os blocos menores assemelham-se àqueles do experimento $\mathrm{MO}-1$, ao passo que os blocos mais largos assemelham-se àqueles do experimento MO-1A (Figura 16). Os blocos menores foram gerados a partir do desenvolvimento de falhas fora de sequência.

No modelo MO-3 a camada de microesferas de vidro, colocada entre duas camadas de areia, comportou-se reologicamente como menos competente do que as camadas de areia, que passaram a representar o material mais competente. Este experimento apresentou o menor número de falhas entre todos os experimentos realizados e, como consequência, apresentou blocos falhados mais largos (Figura 16). Dado ao caráter mais dúctil, a camada de microesfera de vidro teve sua espessura reduzida ao longo da falha, não havendo o desenvolvimento de brechas tectônicas neste material (Figura 13).

O grande número de fotografias (duas por segundo), transformadas em filme, e seu processamento com o PIV permitiu o monitoramento da deformação incremental nos experimentos, sendo possível monitorar o desenvolvimento das estruturas em diversos estágios de desenvolvimento. Assim, a migração da deformação foi monitorada e observou-se

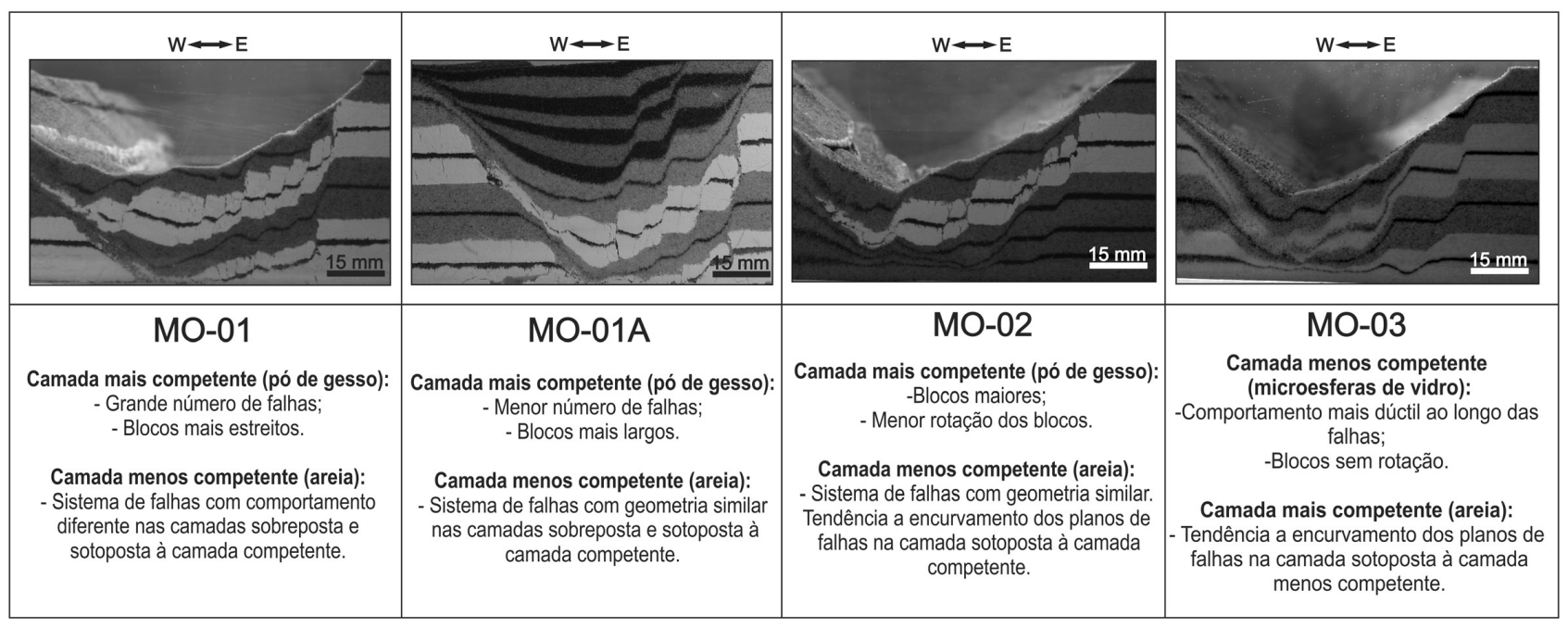

Figura 16. Resumo das principais características de cada um dos experimentos analisados neste trabalho. 


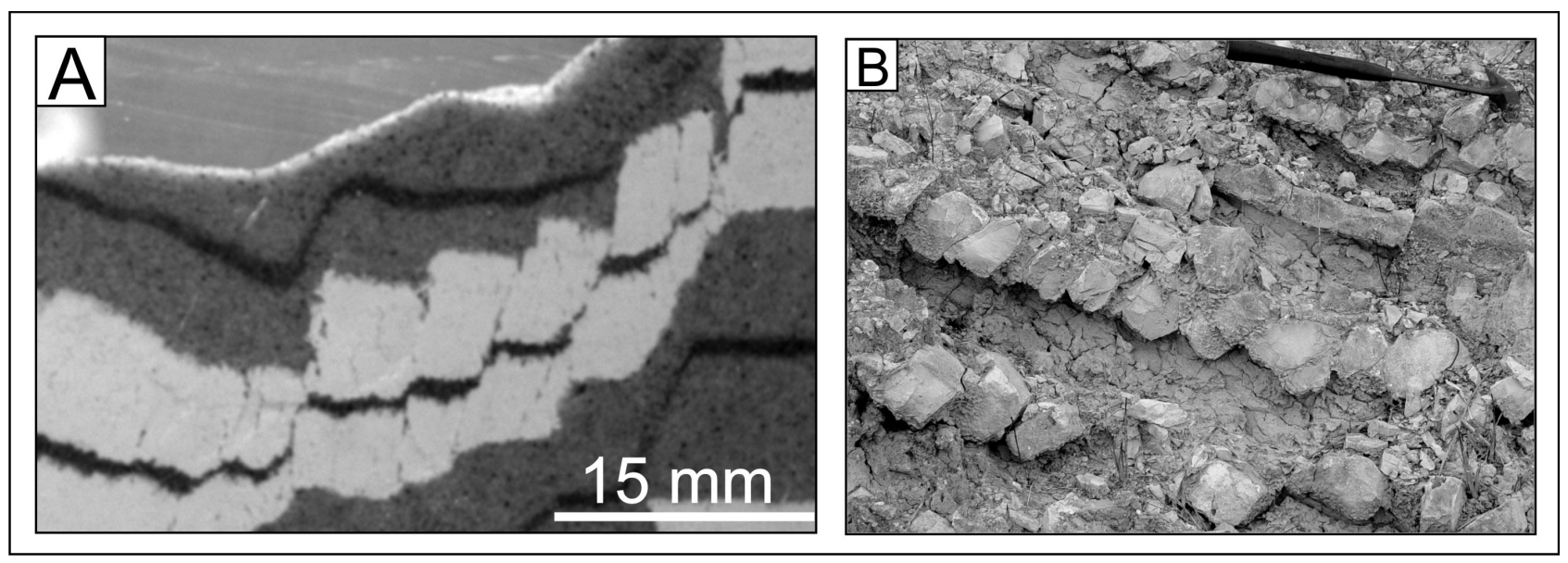

Figura 17. Blocos falhados com arranjo em dominós desenvolvidos em camada competente (pó de gesso) do experimento MO-1 (A) e em carbonatos da Bacia de Sergipe (B).

que algumas falhas ficaram inativas à medida que falhas novas eram criadas (Figura 11). No experimento MO-1, foi possível verificar que a evolução das estruturas frágeis na camada de pó de gesso foi mais lenta nos estágios iniciais (até 2,8\% de distensão) que nos estágios subsequentes. Isto foi interpretado como devido ao fato de que parte do strain foi absorvido pelo material, em função do rearranjo interno dos grãos, antes da formação das estruturas frágeis. $\mathrm{Na}$ natureza, as camadas de litologias competentes, como a de pó de gesso usada nos experimentos, são capazes de acomodar uma maior quantidade de strain pré-quebra (por deslizamento de limites de grãos, colapso de poros e desidratação associada, pressure solution) do que as camadas de litologias menos competentes (Ferrill e Morris, 2008).

Comparando-se os resultados obtidos neste trabalho com alguns dados existentes na literatura, verificou-se que, em afloramentos naturais, muitas vezes as fraturas de distensão são interpretadas como tendo origem relacionada à evolução das falhas normais (Van der Zee et al., 2008). Entretanto, os experimentos aqui realizados mostram justamente o oposto, ou seja, as juntas distensionais desenvolvidas nas camadas mais competentes foram precursoras das falhas. Nossos resultados são, entretanto, compatíveis com aqueles obtidos por Schmatz et al. (2010) em modelagem analógica de sequências multi-camadas saturadas em água.

As camadas de pó de gesso dos experimentos aqui descritos podem ser tomadas como análogas de situações reais, onde camadas de rochas carbonáticas têm comportamento competente em sequências reologicamente estratificadas. Nestas camadas, o desenvolvimento de juntas/fraturas abertas, com geometrias diversas, aumenta sua porosidade, contribuindo para ampliar a circulação de fluidos. Por sua vez, o comportamento das falhas nestas sequências pode representar selos ou condutos que bloqueiam ou permitem a circulação de fluidos. $\mathrm{O}$ arranjo em dominó das estruturas frágeis modeladas (Figura 17A) é relativamente comum em bacias sedimentares, a exemplo do que ocorre com níveis carbonáticos intercalados com níveis margosos em afloramento na Bacia de Sergipe (Figura 17B).

O conhecimento da geometria e distribuição em subsuperfície dessas falhas e juntas associadas são de grande importância na análise de reservatórios petrolíferos. Assim, a modelagem analógica com o uso do PIV, essencial para a visualização da evolução incremental da deformação, pode prover importantes informações sobre essas estruturas.

\section{AGRADECIMENTOS}

M. E. Oliveira agradece ao PRH-22 (ANP) pela bolsa de mestrado no Programa de Pós-Graduação em Geodinâmica e Geofísica (PPGG) da Universidade Federal do Rio Grande do Norte (UFRN). Os autores agradecem também a André Blanco pela ajuda na aquisição e processamento das imagens com PIV e a dois revisores anônimos que muito contribuíram para a melhoria da versão inicial deste trabalho. O Laboratório de Modelagem Física do PPGG recebe apoio do CENPES/PETROBRAS.

\section{REFERÊNCIAS}

Adam, J., Urai, J. L., Wieneke, B., Oncken, O., Pfeiffer, K., Kukowski, N., Lohrmann, J., Hoth, S., Van der Zee, W., Schmatz, J. (2005). Shear localisation and strain distribution during tectonic faulting - new insights from granular-flow experiments and high-resolution optical image correlation techniques. Journal of Structural Geology, 27, 283-301. 
Alves da Silva, F. C., Oliveira, F. J. S. (2009). Desenvolvimento de traços estruturais curvilíneos em cinturões de empurrões: visualização em modelagem física. Revista Brasileira de Geociências, 39(1), 138-150.

Bai, T., Pollard, D. (2000). Closely spaced fractures in layered rocks: initiation mechanism and propagation kinematics. Journal of Structural Geology, 22, 1409-1425.

Berdiel, T. R. (1999). Geometry of granite emplacement in the upper crust: contributions of analogue modelling. Geological Society of London, Special Publications, 168, 77-94.

Berdiel, T. R., Gapais, D., Brun, J. P. (1997). Granite intrusion along strike-slip zones in experiment and nature. American Journal of Science, 297, 651-678.

Blanco, A. J. P. C., Alves da Silva, F. C., Jardim de Sá, E. F. (2014). Desenvolvimento simultâneo de semigrabens ortogonais e oblíquos à direção de distensão: modelagem física de análogo natural no Nordeste brasileiro. Geologia USP. Série Científica, 14(1), 37-54.

Boutelier, D., Chemenda, A. (2011). Physical modeling of arc-continent collision: a review of $2 \mathrm{D}, 3 \mathrm{D}$, purely mechanical and thermo-mechanical experimental models. In: D. Brown, P. D. Ryan, (Eds.), Arc-continent collision, 445-473. Berlin: Springer.

Cappelletti, A., Salvi, F., Meda, M., Cavozzi, C., Chowdhury, B. R., Nestola, Y., Argnani, A., Tsikalas, F., Magistroni, C., Dalla, S., Roveri, M., Bevilacqua, N. (2011). Tectonostratigraphic evolution of South Atlantic extensional rifted margins: constraints from sandbox analogue modeling. AAPG International Conference and Exhibition. Milan.

Corti, G. (2012). Evolution and characteristics of continental rifting: analogue modeling-inspired view and comparison with examples from the East African Rift System. Tectonophysics, 1(33), 522-523.

Currie, J. B., Patnode, H. W., Trump, R. P. (1962). Development of folds in sedimentary strata. Geological Society of America Bulletin, 73, 655-674.

Exner, U., Grasemann, B., Mancktelow, N. S. (2006). Multiple faults in ductile simple shear: analogue models of flanking structure systems. In: S. J. H. Buiter, G. Schreurs, (Eds.), Analogue and Numerical Modelling of Crustal-Scale Processes, 381-395. London: Geological Society. (Special Publications, 253).

Faccenna, C., Davy, P., Brun, J. P., Funiciello, R., Giardini, D., Mattei, M., Nalpas, T. (1996). The Dynamics of backarc extension: an experimental approach to the opening of the Tyrrhenian Sea. Geophysical Journal International, 126, 781-795.
Ferrill, D. A., Morris, A. P. (2008). Fault zone deformation controlled by carbonate mechanical stratigraphy, Balcones fault system, Texas. AAPG Bulletin, 92(3), 359-380.

Fossen, H., Gabrielsen, R. H. (1996). Experimental modeling of extensional fault systems by use of plaster. Journal of Structural Geology, 18(5), 673-687.

Gomes, C. J. S. (2013). Investigating new materials in the context of analog-physical models. Journal of Structural Geology, 46, 158-166.

Hengmao, T. (2012). Sandbox modeling of fault formation and evolution in the Weixinan Sag, Beibuwan Basin, China. Petroleum Science, 9, 121-128.

Henza, A., Withjack, M., Schlische, R. (2011). How do the properties of a pre-existing normal-fault population influence fault development during a subsequent phase of extension? Journal of Structural Geology, 33, 1312-1324.

Keep, M., McClay, K. R. (1997). Analogue modelling of multiphase rift systems. Tectonophysics, 273, 239-270.

Koyi, H. A. (1997). Analogue modelling: from a qualitative to a quantitative technique - a historical outline. Journal of Petroleum Geology, 20(2), 223-238.

Ladeira, F. L., Price, N. J. (1981). Relationship between fracture spacing and bed thickness. Journal of Structural Geology, 3(2), 179-183.

Le Pourhiet, L., Mattioni, L., Moretti, I. (2006). 3D modelling of rifting through a pre-existing stack of nappes in the Gulf of Corinth (Greece): a mixed analogue/numerical approach. In: S. J. H. Buiter, G. Screurs, (Eds.), Analogue and numerical modelling of crustal-scale processes, 233-252. London: Geological Society. (Special Publications, 253).

Liesa, C. L., Soria, A. R., Meléndez, N., Meléndez, A. (2006). Extensional fault control on the sedimentation patterns in a continental rift basin: El Castellar Formation, Galve sub-basin, Spain. Journal of the Geological Society, 163, 487-498.

Lorenz, J. C., Sterling, J. L., Schechter, D. S., Whigham, C. L., Jensen, J. L. (2002). Natural fractures in the Spraberry Formation, Midland Basin, Texas: the effects of mechanical stratigraphy on fracture variability and reservoir behavior. AAPG Bulletin, 86, 505-524.

McClay, K. R., Dooley, T., Gloaguen, R., Whitehouse, P., Khalil, S. (2001). Analogue modelling of extensional fault architectures: comparisons with natural rift fault systems. PESA Eastern Australasian Basins Symposium, 573-584. Melbourne: PESA.

McClay, K. R., Dooley, T., Whitehouse, P., Mills, M. (2002). 4-D evolution of rift systems: insights from scaled physical models. AAPG Bulletin, 86, 935-959. 
McQuillan, H. (1973). Small-scale fracture density in Asmari Formation of southwest Iran and its relation to bed thickness and structural setting. AAPG Bulletin, 57, 2367-2385.

Naylor, M. A., Laroque, J. M., Gauthier, B. D. M. (1994). Understanding extensional tectonics: insights from sandbox models. Geodynamic Evolution of Sedimentary Basins International Symposium, 69-83. Moscow.

Panien, M., Schreurs, G., Pfiffner, A. (2005). Sandbox experiments on basin inversion: testing the influence of basin orientation and basin fill. Journal of Structural Geology, 27, 433-445.

Panien, M., Schreurs, G., Pfiffner, A. (2006). Mechanical behaviour of granular materials used in analogue modelling: insights from grain characterisation, ring-shear tests and analogue experiments. Journal of Structural Geology, 28, 1710-1724.

Peacock, D. C. P., Sanderson, D. J. (1992). Effects of layering and anisotropy on fault geometry. Journal of the Geological Society, 149, 793-802.

Portugal, R. A., Alves da Silva, F. C. (2006). Desenvolvimento, geometria e cinemática de falhas associadas à distensão oblíqua em bacias sedimentares: a contribuição do modelamento físico. $43^{\circ}$ Congresso Brasileiro de Geologia, v. 112. Aracaju: SBG.

Ramsay, J. G., Huber, M. I. (1987). The techniques of modern structural geology. London: Academic Press. (Folds and Fractures, 2).

Rossi, D., Storti, F. (2003). New artificial granular materials for analogue laboratory experiments: aluminium and siliceous microspheres. Journal of Structural Geology, 25, 1893-1899.

Schellart, W. P. (2000). Shear test results for cohesion and friction coefficients for different granular materials: scaling implications for their usage in analogue modelling. Tectonophysics, 324, 1-16.

Schmatz, J., Vrolijk, P. J., Urai, J. L. (2010). Clay smear in normal fault zones - The effect of multilayers and clay cementation in water-saturated model experiments. Journal of Structural Geology, 32, 1834-1849.

Schöpfer, M. P. J., Childs, C., Walsh, J. J. (2006). Localisation of normal faults in multilayer sequences. Journal of Structural Geology, 28, 816-833.

Shemenda, A. I. (2012). Subduction: insights from physical modeling. Springer Science \& Business Media.
Srivastava, H. B., Cobbold, P. R. (2014). What makes India such a good indenter? Research Communications: Current Science, 106(2), 288-292.

Szatmari, P., Aires, J. R. (1987). Experimentos com modelagem física de processos tectônicos no Centro de Pesquisas da Petrobras. Boletim de Geociências da Petrobras, 1, 13-34.

Van der Zee, W., Wibberley, C. A. J., Urai, J. L. (2008). The influence of layering and pre-existing joints on the development of internal structure in normal fault zones: the Lodève basin, France. In: C. A. J. Wibberley, W. Kurz, J. Imber, R. E. Holdworth, C. Collerini (Eds.), The internal structure of fault zones: implications for mechanical and fluid-flow properties, 57-74. London: Geological Society. (Special Publications, 299).

Van Gent, H. (2005). Scaled analogue models of normal faulting in brittle lithologies. Dissertação (Mestrado). Utrecht: Faculty of Geosciences, Utrecht University.

Van Gent, H. W., Holland, M., Urai, J. L., Loosveld, R. (2010). Evolution of fault zones in carbonates with mechanical stratigraphy: insights from scale models using layered cohesive powder. Journal of Structural Geology, 32, 1375-1391.

Vendeville, B., Cobbold, P. R., Davy, P., Brun, J. P., Choukroune, P. (2002). Physical models of extensional tectonics at various scales. In: R. E. Holdsworth, J. P. Turner (Eds.), Extensional tectonics: faulting and related processes, v. 2, 171-183. London: The Geological Society.

Ventisette, C. D., Gigli, G., Bonini, M., Corti, G., Montanari, D., Santoro, S., Sani, F., Fanti, R., Casagli, N. (2015). Insights from analogue modelling into the deformation mechanism of the Vaiont landslide. Geomorphology, 228, 52-59.

Withjack, M. O., Schlische, R. W. (2006). Geometric and experimental models of extensional fault-bend folds. In: S. J. H. Buiter, G. Schreurs (Eds.), Analogue and numerical modelling of crustal-scale processes, 285-305. London: Geological Society. (Special Publications, 253).

Wu, L., Kluth, C. F., Trudgill, B. D. (2013). Oblique Rift System in Caswell Sub-basin, Browse Basin (NW Shelf, Australia): insights from 3-D Seismic Interpretation and Structural Modeling. AAPG Annual Convention and Exhibition. Pittsburgh: AAPG.

Zahm, C. K., Hennings, P. H. (2009). Complex fracture development related to stratigraphic architecture: challenges for structural deformation prediction, Tensleep Sandstone at the Alcova anticline, Wyoming. AAPG Bulletin, 93(11), 1427-1446. 